\title{
New Shape Function Solutions for Fracture Mechanics Analysis of Offshore Wind Turbine Monopile Foundations
}

\author{
Mathieu Bocher ${ }^{1}$, Ali Mehmanparas t ${ }^{1 *}$, Jarryd Braithwaite ${ }^{1}$, Mahmood Shafiee ${ }^{1}$ \\ ${ }^{1}$ Offshore Renewable Energy Engineering Centre, Cranfield University, Cranfield, \\ Bedfordshire MK43 0AL, UK. \\ *Corresponding author: a.mehmanparast@ cranfield.ac.uk
}

\begin{abstract}
Offshore wind turbines are considered one of the most promising solutions to provide sustainable energy. The dominant majority of all installed offshore wind turbines are tied up to the seabed using monopile foundations. To predict the lifetime of these structures, reliable values for shape function and stress intensity factor are needed. In this study, finite element simulations have been performed for a wide range of monopile geometries with different dimensions, crack lengths as well as depths to evaluate shape function and stress intensity factor solutions for monopiles and an empirical equation is developed. The new solutions have been verified through comparison with the existing solutions provided by Newman \& Raju for small hollow cylinders. The empirical shape function solutions developed in this study are employed in a case study and the results have been compared with the existing shape function solutions. It is found that the old solutions provide inaccurate estimations of fatigue crack growth in monopiles and they underestimate or overestimate the fatigue life depending on the shape function solution employed in the structural integrity assessment. The use of the new solution will result in more accurate monopile designs as well as life predictions of existing monopile structures.
\end{abstract}

Keywords: stress intensity factor; shape function; fatigue crack growth; inspection; monopile; offshore wind turbine

\section{Nomenclature}

$\begin{array}{ll}a & \text { Crack depth } \\ b & \text { Half width (in a plate) } \\ c & \text { Half crack length (in a semi-elliptical crack) } \\ D & \text { Pipe or monopile Diameter } \\ E & \text { Elastic Young's modulus } \\ F & \text { Normalised stress intensity factor in Newman \& Raju solution } \\ h & \text { Pipe height } \\ I_{Z} & \text { Second moment of area along the } z \text { axis } \\ K & \text { Stress intensity factor } \\ M_{Z} & \text { Bending moment along the } z \text { axis } \\ Q & \text { Non-dimensional shape factor } \\ R_{\text {in }} & \text { Inner radius } \\ R_{\text {out }} & \text { Outer radius } \\ t & \text { Thickness } \\ y & \text { Distance from the neutral axis } \\ Y & \text { Shape function }\end{array}$




$\begin{array}{ll}\sigma & \text { Applied stress } \\ \sigma_{b} & \text { Bending stress } \\ \sigma_{t} & \text { Tensile stress } \\ \sigma_{\max } & \text { Maximum bending stress } \\ v & \text { Poisson's ratio } \\ \Phi & \text { Circular crack tip angle } \\ \text { BM } & \text { Based Metal } \\ \text { FE } & \text { Finite Element } \\ \text { FP } & \text { Finite Plate } \\ \text { HAZ } & \text { Heat Affected Zone } \\ \text { HC } & \text { Hollow Cylinder } \\ \text { LEFM } & \text { Linear Elastic Fracture Mechanics } \\ \text { MP } & \text { MonoPile } \\ \text { N\&R } & \text { Newman \& Raju Shape Function Solution } \\ \text { OPEX } & \text { OPerational EXpenditure } \\ \text { SIF } & \text { Stress Intensity Factor }\end{array}$

\section{Introduction}

The offshore wind industry has grown exponentially in recent years due to the global energy demand and targets set by the European Union to fulfil at least $20 \%$ of its total energy needs with renewables by 2020 [1]. With large capital costs through the manufacture and installation of offshore wind farms, the levelised cost of energy (LCoE) is high, making it difficult for wind energy to be price-competitive in the energy market. The UK's Department for Bus iness, Energy \& Industrial Strategy (BEIS) (formerly known as Department of Energy and Climate Change (DECC)) have set a challenge for offshore wind to achieve a levelised cost of electricity, which is a measure of the overall competitiveness of different generating technologies, of $£ 100 / \mathrm{MWh}$ by 2020 [2]. Surprising LCoE reductions in 2016, to as low as $€ 49.9 / \mathrm{MWh}$ for the Kriegers Flak and other similar projects in Europe have resulted in exceeding the initial targets and making offshore wind energy prices competitive with onshore wind and alternative sources of energy [3]. Therefore, due to reduction in prices as well as availability of more spaces for installation, better wind flows, and less noise it is expected that the development of offshore wind farms will exponentially increase in the coming years. In 2016, $12.5 \mathrm{GW}$ of new wind energy capacity was installed in the European Union, of which $1.6 \mathrm{GW}$ were installed offshore, increasing the total installed offshore wind energy capacity to $12.6 \mathrm{GW}$ [4]. Currently wind energy accounts for $17 \%$ of Europe's total installed power generation capacity, overtaking coal as the largest form of power generation [4].

With the growing interest in expansion of offshore wind energy in Europe and worldwide, an important area that needs to be considered is the structural design and integrity enhancement of offshore wind turbines, which can contribute to further reduction of the levelised cost of offshore wind energy. Knowing that fatigue and corrosion-fatigue are the dominant failure mechanisms in offshore structures due to the constant exertion of cyclic loading from wind and wave, the uncertainties involved in fracture mechanics analys is of fatigue crack growth, particularly for foundations which are at a higher risk of failure, must be minimised. Support structures make up around 35\% of the total cost of an offshore wind project [5] and monopile foundations in particular have been used for around $75 \%$ of offshore wind turbine installations, making the $m$ an important area for research and development. Design standards for offshore monopiles, which are suitable foundation type for water depth of up to 40m [6], have been developed from the oil and gas industry as this is the only sector with experience of similar offshore structures. The structures used in the oil and gas industry however are 
much smaller than wind turbine monopile foundations which are generally $3-7 \mathrm{~m}$ in diameter. These standards have been derived from the testing of piles of up to $1.22 \mathrm{~m}$ in diameter [7], the results of which have been used to scale up the designs, bringing with them uncertainties in the structural behaviour as well as creating the possibility of over-engineering and different failure modes. The thickness and the diameter of monopiles depend on various parameters such as the water depth, soil composition and characteristics, size of the wind turbine and environmental conditions. The diameter and thickness of some of the current monopiles in various offshore wind farms across Europe have been reported by Laszlo Arany et al [8] and this data is summarised in Figure 1.

Offshore wind turbine monopiles are fabricated by rolling, and then, welding relatively thick structural steel plates in a longitudinal direction to produce "cans" and subsequently welding these cans in a circumferential direction. Characterisation of the surface flaws which often occurs in the form of semi-elliptical shaped cracks initiating at the outer surface of the circumferential weld region and propagating in through-thickness direction need to be carefully considered in the design and inspection of offshore wind turbine monopile foundations. Accurate characterisation of fatigue crack initiation and growth in monopiles can significantly improve the fracture mechanics-based inspection of the current assets, reduce maintenance efforts, reduce the Operational expenditure (OPEX) and optimise the design of future generation of monopiles. A key parameter which is used in fracture mechanics analys is of monopiles is the shape function which is used to calculate the stress intens ity factor (SIF) and subsequently characterise the fatigue crack growth behaviour of the material and build fracture-mechanics based inspection plans accordingly. The shape function and stress intens ity factor solutions for various elliptical and semi-elliptical cracks in inf inite, finite and semi-infinite bodies have been investigated by many researchers. For example Irwin provided solutions for an elliptical crack in an infinite body in [9] using the solution of Sneddon and Green [10] and Wigglesworth [11]. Smith et al [12, 13], Shah and Kobayashi [14] made similar attempts to obtain stress intensity factor solutions for circular, semicircular and elliptical cracks in a semi-infinite body. Moreover, Miyamoto and Miyoshi [15] and Tan and Fenner [16] investigated stress intensity factor solutions for a semi-elliptical crack, in a finite plate using the finite element method and in pressurised cylinders using boundary integral equation method, respectively. Although various researchers have experimentally investigated the fatigue crack growth behaviour in hollow cylindrical structures with circumferential semi-elliptical cracks at the outer surface [17-20], the only relevant fracture mechanics shape function and SIF solutions available to analyse experimental data for such geometry are those proposed by J.C. Newman \& I.S. Raju (N\&R) in 1986 [21]. However, the range of normalised dimensions given in [21] is way below those in monopiles (see Figure 1). The current practice to estimate SIFs in monopiles is to employ the solutions available for finite plate under tension in another publication by $N \& R$ [22], but the accuracy of this simplified assumption to use finite plate solutions for cylindrical monopiles has been never examined. Hence, the aim of this study is to investigate and propose new accurate shape function and stress intensity factor solutions for offshore wind turbine monopile geometries through finite element (FE) modelling, by considering their actual dimensions. The procedure to develop the new solutions are described in this paper and the results are compared with the old solutions proposed by N\&R.

\section{Existing Stress Intensity Factor Solutions for Semi-Elliptical Cracked Geometries}

The stress intensity factor, $K$, is the linear elastic fracture mechanics (LEFM) parameter used to describe the stress distribution ahead of the crack tip when the deformation at the crack tip 
region is dominantly elastic. In 1961, Paris showed that this fracture mechanics parameter can also be used to characterise the crack growth behaviour under fatigue loading conditions [23]. The stress intensity factor for mode I fracture mechanics loading conditions, where the applied load is normal to the crack plane, can be described in the general form as [24]

$$
K_{I}=\sigma \sqrt{\pi a} Y
$$

where $\sigma$ is the global applied stress, $a$ is the crack depth and $Y$ is the shape function, which depends on the geometry of the cracked structure. The existing stress intensity factor solutions for semi-elliptical cracks in various geometries subjected to different loading conditions are described below.

\subsection{Stress intensity factor solution for an embedded elliptical crack in an infinite solid under tension}

In 1957, G.R. Irwin [25] used Sne ddon's earlier work [10] to show that the stress and strain variation ahead of the crack tip in an elastic solid can be described using the stress intensity factor, $K$, suggesting the be low equation to define the stress intensity factor $K(\Phi)$ along the crack front for an embedded elliptical crack in an infinite cracked body under tensile stress $\sigma$ $[9,26]$.

$$
K(\Phi)=\sigma \sqrt{\frac{\pi a}{Q}}\left(\frac{a^{2}}{c^{2}} \cos ^{2}(\Phi)+\sin ^{2}(\Phi)\right)^{1 / 4}
$$

This equation is valid for the crack configuration shown in Figure 2, in which $a$ and $c$ are the semi-elliptical half crack depth and half crack length, respectively, and $\Phi$ is the circular crack tip angle, with respect to the horizontal axis, inside the ellipse. In Equation (2), the term $Q$ is the shape factor for an ellipse and is given by the square of the complete elliptic integral of the second kind.

\subsection{Stress intensity factor solution for a semi-elliptical surface crack in a finite plate under tension}

In 1979, J.C. Newman \& I.S. Raju proposed an empirical stress intensity factor equation for a semi-elliptical surface crack in a finite plate under tensile stress $\sigma_{t}[22]$ in the following form:

$$
K=\sigma_{t} \sqrt{\frac{\pi a}{Q}} F\left(\frac{a}{t}, \frac{a}{c}, \frac{c}{b}, \Phi\right)
$$

This equation was proposed for a semi-elliptical cracked geometry schematically shown in Figure 3, where $a$ is the crack depth, $c$ is the half crack length, $t$ is the plate thickness, $h$ is the half height, $b$ is the half width of the plate and $\Phi$ is the circular crack tip angle inside the semi-ellipse. In Equation (3), the non-dimensional shape factor $Q$ for the semi-ellipse can be approximated by using the estimated equation of $Q$ given in [27]:

$$
Q=1+1.464(a / c)^{1.65} \text { for }(a / c \leq 1)
$$

Also, in Equation (3) the non-dimensional boundary condition factor $F$ can be calculated using the following equation:

where;

$$
F=\left[M_{1}+M_{2}\left(\frac{a}{t}\right)^{2}+M_{3}\left(\frac{a}{t}\right)^{4}\right] g f_{\phi} f_{w}
$$

$$
M_{1}=1.13-0.09\left(\frac{a}{c}\right)
$$




$$
\begin{gathered}
M_{2}=-0.54+\frac{0.89}{0.2+(a / c)} \\
M_{3}=0.5-\frac{1.0}{0.65+\left(\frac{a}{c}\right)}+14\left(1.0-\frac{a}{c}\right)^{24} \\
g=1+\left(0.1+0.35\left(\frac{a}{t}\right)^{2}\right)(1-\sin (\Phi))^{2} \\
f_{\phi}=\left[\left(\frac{a}{c}\right)^{2} \cos ^{2}(\Phi)+\sin ^{2}(\Phi)\right]^{1 / 4} \\
f_{w}=\left[\sec \left(\frac{\pi c}{2 b} \sqrt{\frac{a}{t}}\right)\right]^{1 / 2}
\end{gathered}
$$

Equation (3) is valid for $c / b<0.5,0<a / c \leq 1.0,0 \leq a / t<1.0$ and $0 \leq \Phi \leq \pi$.

\subsection{Stress intensity factor solution for a circumferential semi-elliptical surface crack in a hollow cylinder under bending load}

In 1986, J.C. Newman \& I.S. Raju proposed stress intensity factor solutions for circumferential semi-elliptical surface cracks in pipes (i.e. hollow cylinder (HC)) and rods under bending stresses [21]. The geometry considered for a pipe in [21] is shown in Figure 4 (top view) and Figure 5 (side view) where $a$ is the crack depth, $c$ is the half circumferential semi-elliptical crack length, $t$ is the thickness, $R_{\text {in }}$ is the inner radius of the hollow cylinder, $h$ is the half height and $D$ is the outer diameter (i.e. which is $2 \times R_{\text {out }}$ where $R_{\text {out }}$ is the outer radius) of the hollow cylinder. The crack plane in this study was considered normal to the pipe axis and the crack front was assumed to meet the free surface at a $90^{\circ}$ angle. This assumption was motivated by previous studies which have shown that in rods under remote tension, the crack front was intersecting the free surface at nearly right angles. To obtain the stress intens ity factor, N\&R used three-dimensional FE analys is with Poisson's ratio of 0.3 as the elastic property. They chose a large enough height (i.e. length) $2 h$ for the pipe to have negligible effects on stress intensity factor solutions. The coordinate system used in this study is schematically shown in Figure 6 where the definition of the $\Phi$ angle with respect to the horizontal $x$-axis can be observed. N\&R defined the stress intensity factor at any point at the crack front as

$$
K=\sigma_{b} \sqrt{\pi \frac{a}{Q}} F
$$

where $\sigma_{b}$ is the bending stress, $a$ is the crack depth, $Q$ is the non-dimensional shape factor and $F$ is the non-dimensional boundary condition factor. N\&R have presented their results in terms of the normalised stress intensity factor $\left(K /\left(\sigma_{b} \sqrt{\pi a / Q}\right)\right.$ at the maximum crack depth (see point $\mathrm{A}$ in Figure 4) and at the point which the crack front meets the free surface (see point B in Figure 4). They have also shown the normalised stress intensity factor solutions as a function of the parametric angle $(2 \Phi / \pi)$ for some of the examined dimensions. A summary of N\&R normalised stress intensity factor, $F$, solutions for a circumferential semi-elliptical surface crack in a hollow cylinder under bending stress is given in Table 1 . Note that the results presented in reference [21] are valid for $1 \leq R_{i n} / t \leq 10,0.6 \leq a / c \leq 1.0,0.2 \leq a / t \leq 0.8$.

\section{Finite Element Model Set up for the Monopile Geometry}

As seen above, the stress intensity factor solutions for a circumferential semi-elliptical surface crack in a hollow cylinder under bending stress given by $N \& R$ [21] are only valid for $1 \leq R_{\text {in }} / t \leq 10$. However, the range of the normalised radius for monopiles given in Figure 1 is 
$23 \leq R_{\text {in }} / t \leq 52$ (i.e. $24 \leq R_{\text {out }} / t \leq 53$ ). Another simplified assumption is to take the monopile as a finite plate under tensile stress due to the large size of the geometry and use the solutions for semi-elliptical outer surface cracks provided in [22], though the accuracy of this assumption needs to be examined as the plate geometry does not represent the actual monopile geometry with a curved outer surface. Therefore, there is a need to work out accurate shape function and stress intensity factor solutions for the actual monopile dimensions using FE simulations. In this study, the monopile geometry containing a semielliptical surface crack was modelled in the ABAQUS finite element software package [28]. Similar to the previous work conducted by N\&R [21], the crack front was taken to meet the free surfaces at $90^{\circ}$ angle and the same coordinate system was used in the numerical analyses. In order to develop a general solution for shape function and stress intensity factors for realistic dimensions in monopiles, the outer radius $R_{\text {out }}$, crack depth $a$, monopile thickness $t$ and half circumferential semi-elliptical crack length $c$ parameters were varied by considering a wide range of values for the following normalised parameters $R_{\text {out }} / t, a / t$ and $a / c$. Since the examined dimensional parameters were normalised in the $\mathrm{FE}$ analysis, it was chosen to fix $R_{\text {out }}$ at $5 \mathrm{~m}$ in all simulations and vary the $R_{\text {out }} / t, a / t$ and $a / c$ ratios to determine other parameters accordingly using the equations below:

$$
\begin{gathered}
t=R_{\text {out }} \times \frac{1}{\left(R_{\text {out }} / t\right)} \\
a=t \times(a / t) \\
c=a \times \frac{1}{(a / c)}
\end{gathered}
$$

Moreover, the total length of the monopile $2 h$ was fixed at $40 \mathrm{~m}$. This is a realistic size for a typical offshore wind monopile structure, which is the foundation type suitable for water depth of up to 40m [6], and is large enough to have negligible effects on the stress intensity factor solutions. It is worth noting that only the part of the monopile which is located above the seabed (i.e. excluding the embedded part) was considered for the fracture mechanics analysis in the present study. To cover a wide range of monopile dimens ions and crack sizes, the following range of normalised dimensions were examined in simulations; for $5 \leq R_{\text {out }} / t \leq$ 40 (with increments of 5), $0.4 \leq a / c \leq 1.0$ (with increments of 0.2 ), $0.2 \leq a / t \leq 0.8$ (with increments of 0.3). 96 cracked geometries were created and simulated in this study. It must be noted that the half circumferential semi-elliptical crack length $c$ implemented in FE models was calculated as the arc length at the outer surface of the monopile using $c=R_{\text {out }} \times \alpha$ where $\alpha$ is the central angle in radians.

\subsection{Material properties}

Linear elastic material properties of Young's modulus $E=200 \mathrm{GPa}$ and $v=0.3$, which are typical elastic properties for steel material [29] that monopiles are often made of, were assigned to the monopile geometry. Note that the LEFM stress intensity factor solutions are independent of the elastic properties, though the elastic properties have to be assigned to the model in order to run the FE simulations.

\subsection{Partitioning and meshing strategy}

To accurately determine stress intensity factors from FE simulations, the following partitioning strategy was developed and followed: 
- Step 1: Two datum planes were created on the monopile geometry; the first one at the mid-length of the monopile, where the crack was located, and the second one perpendicular to it along the length of the monopile. To make the mesh generation easier and more structured, two additional datum planes were also created by offsetting the mid-length plane towards top and bottom (see Figure 7(a)).

- Step 2: The crack front was created using a semi-elliptical partition at one side of the monopile geometry. To make the meshing easier and more structured, two additional semi-elliptical partitions were created deeper in the through thickness direction (i.e. crack propagation direction). These semi-elliptical partitions were extruded along the entire length of the monopile (Figure 7(b)).

- Step 3: At one end of the monopile geometry, the circumferential extremity was partitioned and these partitions were extruded along the entire length of the monopile (see Figure 7(c)).

After partitioning the geometry, the monopile was meshed using structured hexagonal elements with reduced integration points (C3D8R) for the region in the neighbourhood of the crack front (between the semi-elliptical partitions) and sweep hexagonal elements for the rest of the geometry. To minimise the number of elements and therefore the computational time needed for each simulation, fine elements of around $0.2 \mathrm{~mm}$ were assigned to the region close to the crack tip and the element size was coarsened away from this region. The variation of the element size post-meshing can be observed in Figure 8 (top view) and Figure 9 (side view).

\subsection{Crack definition}

The crack was modelled in ABAQUS using the crack tool in the intersection module. The qvector method was chosen to define the crack propagation direction. Knowing that the qvector direction changes along the semi-elliptical crack front, a Python code was developed to define appropriate q-vectors normal to the crack plane at different points along the crack line. An example of the q-vector distribution at the crack front is shown in Figure 10. Also, the crack location was chosen to be at the mid-length of the monopile similar to the previous study conducted by N\&R [21] (see Figure 11).

\subsection{Loading and boundary conditions}

To obtain a pure bending loading condition in the monopile geometry, the bottom end of the monopile was fixed us ing the "PINNED" boundary condition (i.e. restricting displacement in all directions: $U 1=U 2=U 3=0$ ) and a moment load was applied to the opposite end (i.e. top end) of the monopile, at the same side as the circumferential semi-elliptical crack was created, as seen in Figure 11. To apply the moment, a reference point was created on the cylinder ax is and a coupling interaction was set between this point and the extremity surface of the cylinder as shown in Figure 12. For a hollow cylinder under a bending load, the maximum bending stress $\sigma_{b}$ at the outer surface can be calculated using [30]:

$$
\sigma_{X X \max }=\frac{M_{z} y}{I_{z}}
$$

where $\sigma_{X X \max }$ is the maximum bending stress along the crack driving force direction ( $x$-axis in Figure 11), $M_{Z}$ is the bending moment along the $z$ axis, $y$ is the distance from the neutral axis, and $I_{z}$ is the second moment of area along the $z$ axis. For a hollow cylinder, the second moment of area is given by the following formula:

$$
I_{z}=\frac{\pi}{4}\left(R_{\text {out }}^{4}-R_{\text {in }}^{4}\right)
$$


where $R_{\text {out }}$ is the outer radius and $R_{\text {in }}$ is the inner radius. By combining Equations (16) and (17), the bending moment for a given maximum bending stress can be calculated as:

$$
M_{z}=\frac{\sigma_{X X \max } \pi\left(R_{\text {out }}{ }^{4}-R_{\text {in }}{ }^{4}\right)}{4 y}
$$

In this study, the maximum bending stress in all simulations was fixed at $200 \mathrm{MPa}$ and the corresponding bending moment was calculated using Equation (18).

\subsection{Stress intensity factor and shape function calculation}

The stress intensity factors (with maximum tangential stress as crack initiation criterion) were calculated by assigning 12 contours ahead of the crack front in FE simulations. It is known that fluctuating values are obtained from the first few contours [31], however a clear convergence in stress intensity factor solutions was observed by increasing the number of contours to 12. By re-arranging the general $K$ definition in Equation (1), the shape function $Y$ can be calculated from the stress intensity factor solution obtained from ABAQUS using:

$$
Y=K /\left(\sigma_{b} \sqrt{\pi a}\right)
$$

where $\sigma_{b}$ is the global bending stress and $a$ is the crack depth.

Compared to N\&R definition of $K$ in Equation (12), the $Q$ term is not presented in the general definition of $K$ described in Equation (19). It must be noted that the $Q$ term originally comes from the the ory of the stress intensity factor of "embedded elliptical" crack in an "infinite solid" under tension. In the case of a semi-elliptical surface crack in a finite plate (see [22]), the semi-major ax is is equal to the half crack length $c$ and the semi-minor axis is equal to the crack depth $a$. Nevertheless, in the case of a circumferential semi-elliptical surface crack in a hollow cylinder, the crack length is not equal to the semi-major axis of the ellipse. Therefore, us ing the $Q$ term definition in Equation (19) would result in some errors in the calculation of the complete elliptic integral of the second kind. Therefore, Equation (19) which doesn't include the $Q$ term has been used in this study to calculate and describe the shape function solutions.

\section{Numerical Shape Function and Stress Intensity Factor Solutions for the Monopile Geometry}

Finite element simulations were performed under $\sigma_{b}=200 \mathrm{MPa}$ on 96 cases of cracked monopiles to evaluate the stress intensity factor solutions for each case. The obtained $K$ solutions from FE simulations were then employed in Equation (19) to calculate the corresponding shape function solutions at the deepest point (denoted point A) and the free surface (denoted point $\mathrm{B}$ ) and the results are summarised in Table 2 for $5 \leq R_{\text {out }} / t \leq 40,0.4 \leq$ $a / c \leq 1.0$ and $0.2 \leq a / t \leq 0.8$.

\subsection{Comparison of the new shape function solutions with Newman \& Raju values for hollow cylinder under bending load}

In order to verify the new solutions obtained from FE simulations on monopile geometry, the new results for relatively small $R_{\text {out }} / t$ values have been compared to those of presented by $N \& R$ for hollow cylinder under bending load in [21]. It must be noted that $N \& R$ provided their solutions in the form of normalised stress intensity factor values, $K /\left(\sigma_{b} \sqrt{\pi a / Q}\right)$, at the deepest point (point $\mathrm{A}$ ) and the free surface point (point $\mathrm{B}$ ) for $1 \leq R_{\text {in }} / t \leq 10$. Therefore, in order to directly compare the shape function solutions from this study (see Equation (19)) with those of available from $N \& R$, the values presented in [21] were multiplied by $1 / \sqrt{Q}$ 
knowing that $Y=F / \sqrt{Q}$. Also, knowing that the results from N\&R study were based on the inner radius $R_{\text {in }}$ whereas the current study is based on the outer radius $R_{\text {out }}$, the shape function solutions at the deepest point for $R_{\text {out }} / t=5$ from the present study have been compared with the existing solutions for $R_{i n} / t=4$ from $N \& \mathrm{R}$ and the results are shown in Figure 13 and Figure 14 for $0.6 \leq a / c \leq 1.0$ and $0.2 \leq a / t \leq 0.8$ solutions at the deepest point and free surface point, respectively. It can be seen in these figures that for the given $R_{\text {out }} / t$, the N\&R and new shape function solutions fall very close to each other and both solutions are strongly dependent on the $a / c$ and $a / t$ ratio. In general, the new solutions have been found in very good agreement with $N \& \mathrm{R}$ values at $R_{\text {out }} / t=5$ with the mean difference of $1.6 \%$ and maximum difference of $3.3 \%$ between the old and new solutions.

In order to examine the variation of the shape function solutions along the crack front, 3 additional simulations were performed on a monopile geometry with $R_{\text {out }} / t=3$ (i.e. $R_{\text {in }} /$ $t=2$ ) and $a / c=1.0$. Three simulations were performed with $a / t=0.2, a / t=0.5$ and $a / t=0.8$ and the results are compared with the $N \& \mathrm{R}$ solutions in Figure 15. The shape function values obtained from these simulations have been presented against the angle between the point at the crack front and the horizontal axis in the schematic geometry shown in Figure 15. As seen in this figure, the shape function values vary along the crack front and the new solutions follow the same trend as those presented by N\&R in [21]. Moreover, it can be seen in this figure that for the examined monopile geometry, lower $Y$ solutions have been found at the deepest point, compared with the free surface point, which is consistent with the trends shown by N\&R.

Although not shown here for brevity, comparis on of the results obtained from the present study with those presented in [32] for $R_{i n} / t=20$ and 40 has shown very good agreement between shape function solutions from these two independent studies. It is worth noting that the results presented in [32] cover a wide range of $R_{\text {in }} / t$ with discrete values of $1,2,5,10$, 20,40 and 80 , however the current study's focus is on offshore wind turbine monopile dimensions typically ranging between $R_{\text {out }} / t$ of 5 and 40 .

\subsection{Influence of bending stress on the shape function solutions}

The key characteristic of the shape function is its independency from the stress level. To examine the stress independency for the new shape function solutions, 12 additional simulations were performed for $R_{\text {out }} / t=40,0.4 \leq a / c \leq 1.0$ (with increments of 0.2 ), $0.2 \leq$ $a / t \leq 0.8$ (with increments of 0.3 ). For these simulations, the bending moment was set to have a global bending stress of $\sigma_{b}=400 \mathrm{MPa}$. The comparison of the shape function values between the two stress levels at the deepest point and the free surface point are presented in Table 3 and Table 4, respectively. As seen in these tables, the shape function has been found independent of the stress level for the range of cracked geometries examined. This confirms the stress independency of the new shape function solutions.

\subsection{Influence of pile rotation on the shape function solutions}

The pile-soil interaction has not been considered in simulations performed in the present study and the fracture mechanics analyses are focussed on the monopile section located above the seabed. However, previous pile-soil interaction studies conducted by other researchers have shown that as the pile diameter $D$ and embedded pile length below the seabed $L$ increase, the deformation at the mudline decreases. Moreover, the safe limit for the tilt angle due to the pile-soil interaction is specified as $0.5^{\circ}$ for the design of offshore wind monopiles [8]. This implies that the large diameter monopiles subjected to lateral loads exhibit an almost rigid behaviour. Although not shown here for brevity, extra simulations were performed as a part of this study to investigate the effect of maximum allowable pile tilt 
angle on $Y$ solutions and the results confirmed that the shape function solutions for $0.5^{\circ}$ tilted monopile are on average around $1 \%$ smaller than those of obtained for vertical pile position. Therefore, the proposed stress independent shape function solutions presented in the current study can be considered valid for large dimeter monopiles subjected to operational lateral loading conditions and the corresponding stress intensity factor ahead of the crack tip can be calculated by measuring the maximum bending stress acting normal to the crack plane at the outer surface of the monopile.

\subsection{Determination of an empirical equation for the shape function solutions at the deepest crack point in monopiles}

In order to formulate the shape function solutions obtained from FE simulations at the deepest crack point, the influence of $R_{\text {out }} / t$ ratio on the shape function values at the deepest point was firstly studied and the results are presented in Figure 16, Figure 17 and Figure 18 for $a / t=0.2, a / t=0.5$ and $a / t=0.8$, respectively. These figures highlight the fact that for a given $a / t$ and $a / c$, the shape function solutions at the deepest crack point (point $\mathrm{A}$ ) converge towards a constant value as the $R_{\text {out }} / t$ ratio increases. The results in these figures imply that for the monopile geometry, the shape function can be assumed to be independent of the $R_{\text {out }} / t$ ratio when $R_{\text {out }} / t \geq 20$. Therefore, the shape function solutions at the largest $R_{\text {out }} / t$ ratio examined in this study $\left(R_{\text {out }} / t=40\right)$ have been taken as the converged solution and these values have been summarised in Table 5 for $0.4 \leq a / c \leq 1.0$ and $0.2 \leq a / t \leq 0.8$.

In order to examine the influence of $a / c$ and $a / t$ ratios on the shape function solution, the converged $Y$ values at $R_{\text {out }} / t=40$ (see Table 5) were plotted against these ratios in Figure 19. To formulate these solutions and present the results in the form of a simple equation, the observed curves in Figure 19 were interpolated using a second order polynomial fit which has been described in the general form in Equation (20), and values of A, B and C coefficients for $a / t=0.2,0.5$ and 0.8 are summarised in Table 6 . Note that the polynomial interpolation between the known data points was customised in order to always have the interpolated values slightly greater, hence more conservative, than the computed value obtained from FE simulations. Also included in Table 6 are the $R^{2}$ (i.e. coefficient of determination) values are very close to 1.0 which confirm the accuracy of the second order polynomial fit made to the numerical data points.

$$
Y=A(a / c)^{2}+B(a / c)+C
$$

Finally, the influence of the $a / t$ ratio on the coefficients $A, B$ and $C$ was studied. For the coefficients $A, B$ and $C$, a second order polynomial fit was made to describe the dependency of the shape function solution on the $a / t$ ratio and the equations are described in Equations (21)-(23). The equation of the second order polynomial fit can also be used to interpolate the results for $0.2 \leq a / t \leq 0.8$ and it ensures that the interpolated values will be slightly higher, and therefore more conservative, than the computed shape function values (i.e. linear interpolation may result in lower values, therefore second order polynomial fit is more suitable).

$$
\begin{gathered}
A=-0.17622(a / t)^{2}+1.32106(a / t)-0.02133 \\
B=0.54961(a / t)^{2}-2.76876(a / t)-0.28716 \\
C=-0.38333(a / t)^{2}+1.50500(a / t)+0.96933
\end{gathered}
$$


By using the proposed equations given above to calculate the shape function and subsequently stress intensity factor for monopiles with $R_{\text {out }} / t \geq 20$, the mean error between the calculated values given by the empirical equation and the computed values obtained from FE simulations is only $2.0 \%$ which is negligible. Though, when the above empirical equations are used to calculate the shape function at lower values of $R_{\text {out }} / t$ the percentage error increases and reaches $12.3 \%$ for $R_{\text {out }} / t=5$. A comparison between the computed $Y$ values obtained for $R_{\text {out }} / t=40$ and the calculated trend using Equation (20) is shown in Figure 19 for example. As seen in this figure the calculated solutions are in excellent agreement with the computed values. Note that considering the range of $R_{\text {out }} / t$ in monopiles which is between 24 and 53 (see Figure 1), the proposed solution in Equations (20)-(23) which has been derived based on $R_{\text {out }} / t \geq 20$ is valid for all monopiles.

\subsection{Difference between empirical shape function equation for monopile and Newman \& Raju solutions for a finite plate and hollow cylinder}

As mentioned earlier, for the large diameter offshore wind turbine monopile structures a simplistic assumption is to take the circumferential semi-elliptical surface crack as a semielliptical surface crack in a finite plate under tension. Therefore, the empirical solutions of the shape function at the deepest crack point calculated using Equations (20)-(23) for the monopile geometry (MP) are compared with the N\&R solutions for a finite plate (FP) under tension provided in [22] considering $\Phi=90^{\circ}$ (i.e. deepest crack point) and the results are shown and compared in Figure 20. Also included in this figure are the shape function solutions provided by $\mathrm{N} \& \mathrm{R}$ for a hollow cylinder $(\mathrm{HC})$ with $R_{\text {in }} / t=10$ (i.e. $R_{\text {out }} / t=11$ ) which is the largest $R_{\text {in }} / t$ ratio considered in [21]. It can be seen in this figure that the shape function values given by $N \& R$ solutions for finite plate and $N \& R$ solutions for hollow cylinder are always above and below the values obtained from the proposed new empirical equation for monopiles (Equations (20)-(23)), respectively. The mean difference between the FP and MP shape function solutions is $2.9 \%$ with the maximum difference of $8.2 \%$. Similarly, the mean difference between the HC and MP shape function solutions is $4.3 \%$ with the maximum difference of $7.3 \%$. Note that in order to directly compare the shape function solutions from this study with those of available from $N \& R$, the values presented in [22] were multiplied by $1 / \sqrt{Q}$. It must also be noted that the $c / b$ from ref [22] cannot be directly transposed to the monopile geometry as there is no flat "width" in monopile (see Figure 3). This ratio is only used for the width correction factor in Equation (11) and as show $\mathrm{n}$ in Figure 21 the width correction factor in $\mathrm{N} \& \mathrm{R}$ solution $f_{w}$ tends to 1 when $c / b$ ratio tends to 0 (i.e. when $b$ tends to infinity). Therefore, $f_{w}$ has been taken as 1 to compare N\&R shape function solutions with those obtained from the empirical solution for the monopile geometry.

\section{Case study: Fracture Mechanics Based Fatigue Crack Growth Inspection in a Monopile}

In order to investigate the influence of the new shape function and stress intensity factor solutions on the structural integrity assessment of offshore wind turbine monopiles a case study has been presented in this paper. It is considered that a monopile made of S355 structural steel with an outer dia meter of $5 \mathrm{~m}$, thickness of $90 \mathrm{~mm}$, and a circumferential semielliptical crack at the outer surface with a fixed aspect ratio of $a / c=0.6$ is subjected to a cyclic nominal stress range of $\Delta \sigma=100 \mathrm{MPa}$. In order to build a fracture mechanics based inspection plan (see e.g. [33]) for this monopile, the integrated form of Paris law [23] is often employed to estimate the crackextension against number of cycles: 


$$
N_{i+1}-N_{i}=\frac{1}{C \Delta \sigma^{m} \pi^{m / 2}} \int_{a_{i}}^{a_{i+1}} a^{-m / 2} Y^{-m} d a
$$

where $Y$ is the shape function, $C$ and $m$ are the Paris law constants which depend on the material, environment and stress ratio, $N_{i}$ is the number of loading cycles to reach a crack size of $a_{i}$ and $N_{i+1}$ is the number of loading cycles to reach a crack size of $a_{i+1}$. In order to estimate the crack growth behaviour in a monopile, Equation (24) has been used to calculate the number of cycles corresponding to an increment of crack growth using the $C$ and $m$ values for S355 base metal (BM) and heat affected zone (HAZ) given for monopiles in freecorrosion environment reported in [34]. To investigate the change in inspection plan due to the shape function solution, the following four assumptions were employed in fatigue crack growth calculations using Equation (24):

i. $\quad Y=1$ (a very simple assumption used by some researchers e.g. [35, 36])

ii. $\quad Y$ is obtained from N\&R solution for hollow cylinder (HC), with $R_{\text {out }} / t=11\left(R_{\text {in }} / t=\right.$ $10)$, under bending load [21]

iii. $\quad Y$ is obtained from N\&R solution for finite plate (FP) in tension (Equation (3)) [22]

iv. $\quad Y$ calculated using the new empirical equation for monopiles (MP) developed in the present study (Equation (20))

The estimated crack propagation against number of cycles calculated using different shape function solutions are presented in Figure 22 and Figure 23 for the BM and HAZ, respectively. Note that since Equation (20) is valid for $0.2 \leq a / t \leq 0.8$, the initial and final crack size were taken as $18 \mathrm{~mm}$ and $72 \mathrm{~mm}$, respectively, to consider the valid range in the analysis. Als o to employ the empirical $Y$ solution for monopile, Equation (20) was employed in the analysis and the integral was calculated using Matlab. It can be observed in Figure 22 that to get to a crack depth of $72 \mathrm{~mm}$ from an initial crack size of $18 \mathrm{~mm}$ in the BM, when $Y=1$ and N\&R solution for FP are employed in calculations the number of cycles is underestimated by around $37 \%$ and $6 \%$, respectively, compared to the new $Y$ solutions for monopiles, whereas the N\&R solution for HC overestimates the number of cycles by $10 \%$. Similarly, it can be seen in Figure 23 that for the same crack size in the HAZ material, the number of cycles calculated based on $Y=1$ and N\&R solution for FP is underestimated by around $33 \%$ and $7 \%$, respectively, whereas the N\&R $Y$ solution for $\mathrm{HC}$ overestimates the number of cycles by $6 \%$. The results in Figure 22 and Figure 23 show that the shape function solution used in fracture mechanics based inspection of monopiles plays a significant role in life assessment of these structures and the values employed in the analysis can considerably underestimate or overestimate the number of cycles required to reach to a certain crack depth. It is also evident that $Y=1$ and N\&R FP assumptions always underestimate the number of cycles corresponding to a given crack length, whereas N\&R HC assumption overestimates the number of cycles required to obtain a certain crack depth in monopile. The results from this case study suggest that the N\&R FP assumption might be acceptable but slightly underestimates the number of loading cycles compared to the values given when using the new empirical shape function equation for monopile.

\section{Conclusions}

Finite element simulations were performed to evaluate the shape function and stress intensity factor solutions for circumferential semi-elliptical surface cracks in offshore wind turbine monopile (i.e. large diameter hollow cylinder) geometry. A wide range of geometries and dimensions were considered in the analysis to cover the wide range of existing monopiles operating in offshore wind farms around the world. An empirical shape function equation for the deepest point was developed for monopiles based on the finite element results. This 
equation is valid for monopiles with $R_{\text {out }} / t \geq 20,0.2 \leq a / t \leq 0.8$ and $0.4 \leq a / c \leq 1.0$. The developed equation was verified through comparison with Newman \& Raju solutions available for hollow cylinders under bending with small $R_{\text {out }} / t$ ratio. Finally, a case study was considered to determine the significance of shape function solutions employed in estimating fatigue crack growth behaviour in offshore wind turbine monopiles. It appears from the case study that the assumption to use shape function values given by Newman \& Raju for finite plate under tension might be acceptable but slightly underestimates the number of loading cycles compared to the values given when using the new empirical shape function equation for monopile. Moreover, the case study results show that using Newman \& Raju shape function values for small diameter hollow cylinders (i.e. $R_{\text {out }} / t=11$ ) under bending the number of loading cycles are overestimated by up to $10 \%$ and for $Y=1$ the number of estimated cycles is out by up to $37 \%$, therefore these shape function solutions are unacceptable.

\section{Acknowledgements}

This work was supported by grant EP/L016303/1 for Cranfield University and the University of Oxford, Centre for Doctoral Training in Renewable Energy Marine Structures - REMS (http://www.rems-cdt.ac.uk/) from the UK Engineering and Physical Sciences Research Council (EPSRC). 


\section{References}

[1] National Renewable Energy Action Plan for the United Kingdom: Article 4 of the Renewable Energy Directive. United Kingdom2009.

[2] Electricity Generation Costs. In: Change DoEC, editor. United Kingdom2013.

[3] The Global Wind Energy Council's (GWEC) Global Wind Report:Annual Market Update 2016. 2016.

[4] Europe W. Wind in power. 2016 European statistics. 2016.

[5] Esteban M, Couñago B, López-Gutiérrez J, Negro V, Vellisco F. Gravity based support structures for offshore wind turbine generators: Review of the installation process. Ocean Engineering. 2015;110:281-91.

[6] Li L, Gao Z, Moan T. Numerical simulations for installation of offs hore wind turbine monopiles using floating ves sels. ASMEPaper No OMAE2013-11200. 2013.

[7] Doherty P, Gavin K. Laterally loaded monopile design for offs hore wind farms. 2011.

[8] Arany L, Bhattacharya S, Macdonald J, Hogan S. Design of monopiles for offshore wind turbines in 10 steps. Soil Dynamics and Earthquake Engineering. 2017;92:126-52.

[9] Irwin GR. Crack-extension force for a part-through crack in a plate. Journal of Applied Mechanics. 1962;29:651-4.

[10] Sneddon IN, Green AE. The distribution of stress in the neighbourhood of a crack in an elastic solid. Proceedings of the Royal Society of London Series A Mathematical and Physical Sciences. 1946; 187:229-60.

[11] Wigglesworth L. Stress distribution in a notched plate. Mathematika. 1957;4:76-96.

[12] Smith FW, Emery AF, Kobayashi AS. Stress Intensity Factors for Semicircular Cracks: Part 2-SemiInfinite Solid. Journal of Applied Mechanics. 1967;34:953-9.

[13] Smith F, Alavi M. Stress intensity factors for a penny shaped crack in a half space. Engineering Fracture Mechanics. 1971;3:241-54.

[14] Shah R, Kobayashi A. Stress intensity factors for an elliptical crack approaching the surface of a semiinfinite solid. International Journal of Fracture. 1973;9:133-46.

[15] Miyamoto H, Miyoshi T. Analysis of stress intensity factor for surface-flawed tension plate. High speed computing of elastic structures. 1971:137-55.

[16] Tan CL, Fenner RT. Stress intensity factors for semi-elliptical surface cracks in pressurised cylinders using the boundary integral equation method. International Journal of Fracture. 1980;16:233-45.

[17] Shahani AR, Shodja MM, Shahhosseini A. Experimental Investigation and Finite Element Analysis of Fatigue Crack Growth in Pipes Containing a Circumferential Semi-elliptical Crack Subjected to Bending. Experimental Mechanics. 2010;50:563-73.

[18] Brighenti R, Carpinteri A. Surface cracks in fatigued structural components: a review. Fatigue \& Fracture of Engineering Materials \& Structures. 2013;36:1209-22.

[19] Paffumi E, Nilss on K-F, Szaraz Z. Experimental and numerical assessment of thermal fatigue in 316 aus tenitic steel pipes. En gineering Failure Analy sis. 2015;47:312-27.

[20] Sahu VK, Ray PK, Verma BB. Experimental fatigue crack growth analysis and modelling in part-through circumferentially pre-cracked pipes under pure bending load. Fatigue \& Fracture of Engineering Materials \& Structures. 2017;40:1154-63.

[21] Raju I, Newman J. Stress-intensity factors for circumferential surface cracks in pipes and rods under tension and bending loads. Fracture Mechanics: Seventeenth Volume: ASTM International; 1986.

[22] Newman Jr J, Raju I. Analysis of surface cracks in finite plates under tension or bending loads. United States:NASA-TP-1578,L-13053; 1979.

[23] Paris PC, Gomez MP, Anderson WP. A rational analytic theory of fatigue. The Trend in Engineering. 1961;13:9-14.

[24] Anderson TL. Fracture Mechanics: Fundamentals and Application. Boston: CRC Press; 1991.

[25] Irwin GR. Analys is of Stresses and Strains Near the End of a Crack Traversing a Plate. Joumal of Applied Mechanics. 1957;24:361-4.

[26] Tada H, Paris, P. C. and Irwin, G. R. The Stress Analysis of Cracks Handbook. Saint Louis: Paris Productions \& (Del Research Corp.); 1985.

[27] Merkle J. Review of some of the existing stress intensity factor solutions for part-through surface cracks. Oak Ridge NationalLab., Tenn.; 1973.

[28] ABAQUS. User Manual. in Version 6.14 ed: in Version 6.14, SIMULIA; 2016.

[29] Gere JM, Goodno BJ. Mechanics of Materials (Cengage Learning, Toronto, 2009). 2009.

[30] Bowes WH, Russell LT, Suter GT. Mechanics of engineering materials. JOHN W ILEY \& SONS, INC, 605 THIRD A VE NEW YORK, NY 10158, USA, 1984, 672. 1984.

[31] Mehmanparast A, Biglari F, Davies CM, Nikbin KM. An Investigation of Irregular Crack Path Effects on Fracture Mechanics Parameters Using a Grain Microstructure Meshing Technique. Joumal of Multiscale Modelling. 2012;4: p 1250001-21. 
[32] Chapuliot S. Formulaire de KI pour les tubes comportant un defaut de surface semi-elliptique longitudinal ou circonferentiel, interne ou externe. CEA, Rapport CEA. 2000.

[33] Doshi K, Roy T, Parihar YS. Reliability based inspection planning using fracture mechanics based fatigue evaluations for ship structural details. Marine Structures. 2017;54:1-22.

[34] Mehmanparast A, Brennan F, Tavares I. Fatigue crack growth rates for offs hore wind monopile weldments in air and seawater: SLIC inter-laboratory test results. Materials \& Design. 2017;114:494-504.

[35] Ziegler L, Schafhirt S, Scheu M, Muskulus M. Effect of load sequence and weather seasonality on fatigue crack growth for monopile-based offs hore wind turbines. Energy Procedia. 2016;94:115-23.

[36] Kirkemo F. Applications of Probabilistic Fracture Mechanics to Offshore Structures. Applied Mechanics Reviews. 1988;41:61-84. 


\section{Tables}

Table 1: A summary of N\&R normalised stress intensity factor, $F$, values for a circumferential semi-elliptical surface crack under bending load [21]

\begin{tabular}{|c|c|c|c|c|c|c|c|}
\hline & & \multicolumn{2}{|c|}{$a / t=0.2$} & \multicolumn{2}{|c|}{$a / t=0.5$} & \multicolumn{2}{|c|}{$a / t=0.8$} \\
\hline$R_{\text {in }} / t$ & $R_{\text {out }} / t$ & Point $A$ & Point B & Point $\mathrm{A}$ & Point B & Point $\mathrm{A}$ & Point B \\
\hline & \multicolumn{7}{|c|}{$a / c=1.0$} \\
\hline 1 & 2 & 0.943 & 1.136 & 0.856 & 1.162 & 0.777 & 1.233 \\
\hline 2 & 3 & 0.966 & 1.137 & 0.919 & 1.188 & 0.870 & 1.287 \\
\hline 4 & 5 & 0.981 & 1.133 & 0.971 & 1.204 & 0.950 & 1.327 \\
\hline 10 & 11 & 0.995 & 1.131 & 1.012 & 1.212 & 1.019 & 1.348 \\
\hline & \multicolumn{7}{|c|}{$a / c=0.8$} \\
\hline 1 & 2 & 0.989 & 1.037 & 0.931 & 1.079 & 0.885 & 1.162 \\
\hline 2 & 3 & 1.007 & 1.037 & 0.984 & 1.107 & 0.966 & 1.224 \\
\hline 4 & 5 & 1.021 & 1.033 & 1.028 & 1.126 & 1.033 & 1.276 \\
\hline 10 & 11 & 1.032 & 1.032 & 1.064 & 1.136 & 1.088 & 1.303 \\
\hline & \multicolumn{7}{|c|}{$a / c=0.6$} \\
\hline 1 & 2 & 1.042 & 0.919 & 1.034 & 0.980 & 1.094 & 1.078 \\
\hline 2 & 3 & 1.056 & 0.919 & 1.069 & 1.015 & 1.118 & 1.152 \\
\hline 4 & 5 & 1.065 & 0.916 & 1.102 & 1.039 & 1.155 & 1.220 \\
\hline 10 & 11 & 1.071 & 0.913 & 1.130 & 1.051 & 1.188 & 1.257 \\
\hline
\end{tabular}

Table 2: Shape function, $Y$, solutions at the deepest point (A) and free surface (B) for the monopile geometry

\begin{tabular}{|c|c|c|c|c|c|c|}
\hline & \multicolumn{6}{|c|}{$a / c=0.4$} \\
\hline & \multicolumn{2}{|c|}{$a / t=0.2$} & \multicolumn{2}{|c|}{$a / t=0.5$} & \multicolumn{2}{|c|}{$a / t=0.8$} \\
\hline$R_{\text {out }} / t$ & Point $\mathrm{A}$ & Point $B$ & Point A & Point $\mathrm{B}$ & Point $A$ & Point $\mathrm{B}$ \\
\hline 5 & 0.940 & 0.654 & 1.042 & 0.719 & 1.154 & 0.803 \\
\hline 10 & 0.954 & 0.665 & 1.078 & 0.787 & 1.187 & 0.979 \\
\hline 15 & 0.961 & 0.677 & 1.094 & 0.807 & 1.202 & 1.031 \\
\hline 20 & 0.961 & 0.680 & 1.098 & 0.816 & 1.204 & 1.053 \\
\hline 25 & 0.963 & 0.685 & 1.104 & 0.831 & 1.208 & 1.083 \\
\hline 30 & 0.958 & 0.688 & 1.099 & 0.821 & 1.207 & 1.068 \\
\hline 35 & 0.967 & 0.709 & 1.102 & 0.832 & 1.207 & 1.090 \\
\hline \multirow[t]{3}{*}{40} & 0.963 & 0.696 & 1.106 & 0.844 & 1.210 & 1.105 \\
\hline & \multicolumn{6}{|c|}{$a / c=0.6$} \\
\hline & \multicolumn{2}{|c|}{$a / t=0.2$} & \multicolumn{2}{|c|}{$a / t=0.5$} & \multicolumn{2}{|c|}{$a / t=0.8$} \\
\hline$R_{\text {out }} / t$ & Point $\mathrm{A}$ & Point B & Point $A$ & Point B & Point $\mathrm{A}$ & Point B \\
\hline 5 & 0.823 & 0.724 & 0.863 & 0.814 & 0.901 & 0.961 \\
\hline 10 & 0.836 & 0.731 & 0.890 & 0.834 & 0.930 & 1.021 \\
\hline 15 & 0.842 & 0.736 & 0.903 & 0.844 & 0.943 & 1.032 \\
\hline 20 & 0.841 & 0.742 & 0.906 & 0.848 & 0.948 & 1.042 \\
\hline 25 & 0.845 & 0.742 & 0.911 & 0.852 & 0.951 & 1.048 \\
\hline 30 & 0.839 & 0.721 & 0.906 & 0.847 & 0.949 & 1.048 \\
\hline 35 & 0.846 & 0.745 & 0.910 & 0.850 & 0.952 & 1.055 \\
\hline 40 & 0.844 & 0.731 & 0.912 & 0.869 & 0.954 & 1.050 \\
\hline
\end{tabular}




\begin{tabular}{|c|c|c|c|c|c|c|}
\hline & \multicolumn{6}{|c|}{$a / c=0.8$} \\
\hline & \multicolumn{2}{|c|}{$a / t=0.2$} & \multicolumn{2}{|c|}{$a / t=0.5$} & \multicolumn{2}{|c|}{$a / t=0.8$} \\
\hline$R_{\text {out }} / t$ & Point $A$ & Point $B$ & Point $A$ & Point B & Point $A$ & Point B \\
\hline 5 & 0.724 & 0.739 & 0.733 & 0.810 & 0.737 & 0.928 \\
\hline 10 & 0.736 & 0.741 & 0.759 & 0.817 & 0.770 & 0.959 \\
\hline 15 & 0.743 & 0.746 & 0.770 & 0.825 & 0.785 & 0.967 \\
\hline 20 & 0.741 & 0.745 & 0.772 & 0.825 & 0.789 & 0.969 \\
\hline 25 & 0.748 & 0.726 & 0.778 & 0.829 & 0.794 & 0.972 \\
\hline 30 & 0.742 & 0.722 & 0.776 & 0.825 & 0.793 & 0.970 \\
\hline 35 & 0.747 & 0.785 & 0.780 & 0.826 & 0.795 & 0.975 \\
\hline \multirow[t]{3}{*}{40} & 0.751 & 0.692 & 0.780 & 0.841 & 0.797 & 0.973 \\
\hline & \multicolumn{6}{|c|}{$a / c=1.0$} \\
\hline & \multicolumn{2}{|c|}{$a / t=0.2$} & \multicolumn{2}{|c|}{$a / t=0.5$} & \multicolumn{2}{|c|}{$a / t=0.8$} \\
\hline$R_{\text {out }} / t$ & Point $A$ & Point B & Point $\mathrm{A}$ & Point B & Point $A$ & Point B \\
\hline 5 & 0.642 & 0.730 & 0.636 & 0.784 & 0.624 & 0.873 \\
\hline 10 & 0.655 & 0.733 & 0.661 & 0.791 & 0.660 & 0.894 \\
\hline 15 & 0.659 & 0.702 & 0.672 & 0.797 & 0.674 & 0.899 \\
\hline 20 & 0.662 & 0.725 & 0.674 & 0.792 & 0.679 & 0.896 \\
\hline 25 & 0.667 & 0.685 & 0.681 & 0.799 & 0.685 & 0.898 \\
\hline 30 & 0.662 & 0.705 & 0.679 & 0.795 & 0.685 & 0.900 \\
\hline 35 & 0.663 & 0.710 & 0.683 & 0.795 & 0.687 & 0.904 \\
\hline 40 & 0.669 & 0.690 & 0.682 & 0.810 & 0.689 & 0.905 \\
\hline
\end{tabular}

Table 3: Stress intensity factor and shape function values at the deepest point (point A) for two stress levels for $R_{\text {out }} / t=40$

\begin{tabular}{|c|c|c|c|c|c|}
\hline \multicolumn{2}{|c|}{ Geometry } & \multicolumn{2}{c|}{$\mathbf{2 0 0} \mathbf{M P a}$} & \multicolumn{2}{c|}{$\mathbf{4 0 0} \mathbf{M P a}$} \\
\hline $\boldsymbol{a} / \boldsymbol{c}$ & $\boldsymbol{a / t}$ & $\boldsymbol{K}(\mathbf{M P a} \cdot \sqrt{\boldsymbol{m}})$ & $\boldsymbol{Y}$ & $\boldsymbol{K}(\mathbf{M P a} \cdot \sqrt{\boldsymbol{m}})$ & $\boldsymbol{Y}$ \\
\hline $\mathbf{0 . 4}$ & $\mathbf{0 . 2}$ & 54.046 & 0.963 & 108.092 & 0.963 \\
\hline $\mathbf{0 . 4}$ & $\mathbf{0 . 5}$ & 97.864 & 1.106 & 195.694 & 1.106 \\
\hline $\mathbf{0 . 4}$ & $\mathbf{0 . 8}$ & 135.286 & 1.210 & 270.572 & 1.210 \\
\hline $\mathbf{0 . 6}$ & $\mathbf{0 . 2}$ & 47.414 & 0.844 & 94.829 & 0.844 \\
\hline $\mathbf{0 . 6}$ & $\mathbf{0 . 5}$ & 80.874 & 0.912 & 161.729 & 0.912 \\
\hline $\mathbf{0 . 6}$ & $\mathbf{0 . 8}$ & 106.901 & 0.954 & 213.802 & 0.954 \\
\hline $\mathbf{0 . 8}$ & $\mathbf{0 . 2}$ & 42.186 & 0.751 & 84.371 & 0.751 \\
\hline $\mathbf{0 . 8}$ & $\mathbf{0 . 5}$ & 69.169 & 0.780 & 138.311 & 0.780 \\
\hline $\mathbf{0 . 8}$ & $\mathbf{0 . 8}$ & 89.359 & 0.797 & 178.717 & 0.797 \\
\hline $\mathbf{1 . 0}$ & $\mathbf{0 . 2}$ & 37.468 & 0.669 & 74.936 & 0.669 \\
\hline $\mathbf{1 . 0}$ & $\mathbf{0 . 5}$ & 60.453 & 0.682 & 120.934 & 0.682 \\
\hline $\mathbf{1 . 0}$ & $\mathbf{0 . 8}$ & 77.222 & 0.689 & 154.443 & 0.689 \\
\hline
\end{tabular}

Table 4: Stress intensity factor and shape function values at the free surface point (point B) for two stress levels for $R_{\text {out }} / t=40$

\begin{tabular}{|c|c|c|c|c|c|}
\hline \multicolumn{2}{|c|}{ Geometry } & \multicolumn{2}{c|}{$200 \mathrm{MPa}$} & \multicolumn{2}{c|}{ 400 MPa } \\
\hline $\boldsymbol{a} / \boldsymbol{c}$ & $\boldsymbol{a / t}$ & $\boldsymbol{K}(\mathrm{MPa} \cdot \sqrt{\boldsymbol{m}})$ & $\boldsymbol{Y}$ & $\boldsymbol{K}(\mathrm{MPa} \cdot \sqrt{\boldsymbol{m}})$ & $\boldsymbol{Y}$ \\
\hline $\mathbf{0 . 4}$ & $\mathbf{0 . 2}$ & 35.508 & 0.696 & 71.016 & 0.696 \\
\hline $\mathbf{0 . 4}$ & $\mathbf{0 . 5}$ & 74.107 & 0.844 & 148.213 & 0.844 \\
\hline
\end{tabular}




\begin{tabular}{|l|c|c|c|c|c|}
\hline $\mathbf{0 . 4}$ & $\mathbf{0 . 8}$ & 123.747 & 1.105 & 247.493 & 1.105 \\
\hline $\mathbf{0 . 6}$ & $\mathbf{0 . 2}$ & 37.621 & 0.731 & 75.242 & 0.731 \\
\hline $\mathbf{0 . 6}$ & $\mathbf{0 . 5}$ & 76.398 & 0.869 & 152.795 & 0.869 \\
\hline $\mathbf{0 . 6}$ & $\mathbf{0 . 8}$ & 117.975 & 1.050 & 235.949 & 1.050 \\
\hline $\mathbf{0 . 8}$ & $\mathbf{0 . 2}$ & 39.412 & 0.692 & 78.823 & 0.692 \\
\hline $\mathbf{0 . 8}$ & $\mathbf{0 . 5}$ & 73.869 & 0.841 & 147.740 & 0.841 \\
\hline $\mathbf{0 . 8}$ & $\mathbf{0 . 8}$ & 109.201 & 0.973 & 218.407 & 0.973 \\
\hline $\mathbf{1 . 0}$ & $\mathbf{0 . 2}$ & 39.326 & 0.690 & 78.653 & 0.690 \\
\hline $\mathbf{1 . 0}$ & $\mathbf{0 . 5}$ & 69.806 & 0.810 & 139.613 & 0.810 \\
\hline $\mathbf{1 . 0}$ & $\mathbf{0 . 8}$ & 101.528 & 0.905 & 203.051 & 0.905 \\
\hline
\end{tabular}

Table 5: The converged solutions of the shape function at the deepest crack point (point A) for sufficiently large $R_{\text {out }} / t$ ratios of equal to and greater than 20

\begin{tabular}{|c|c|c|}
\hline $\boldsymbol{a} / \boldsymbol{c}$ & $\boldsymbol{a} / \boldsymbol{t}$ & $\boldsymbol{Y}$ \\
\hline $\mathbf{0 . 4}$ & $\mathbf{0 . 2}$ & 0.963 \\
\hline $\mathbf{0 . 6}$ & $\mathbf{0 . 2}$ & 0.844 \\
\hline $\mathbf{0 . 8}$ & $\mathbf{0 . 2}$ & 0.751 \\
\hline $\mathbf{1 . 0}$ & $\mathbf{0 . 2}$ & 0.669 \\
\hline $\mathbf{0 . 4}$ & $\mathbf{0 . 5}$ & 1.106 \\
\hline $\mathbf{0 . 6}$ & $\mathbf{0 . 5}$ & 0.912 \\
\hline $\mathbf{0 . 8}$ & $\mathbf{0 . 5}$ & 0.780 \\
\hline $\mathbf{1 . 0}$ & $\mathbf{0 . 5}$ & 0.682 \\
\hline $\mathbf{0 . 4}$ & $\mathbf{0 . 8}$ & 1.210 \\
\hline $\mathbf{0 . 6}$ & $\mathbf{0 . 8}$ & 0.954 \\
\hline $\mathbf{0 . 8}$ & $\mathbf{0 . 8}$ & 0.797 \\
\hline $\mathbf{1 . 0}$ & $\mathbf{0 . 8}$ & 0.689 \\
\hline
\end{tabular}

Table 6: Shape function solution second order polynomial fit coefficient values for various $a / t$ ratios

\begin{tabular}{|l|c|c|c|c|}
\hline $\boldsymbol{a} / \boldsymbol{t}$ & $\boldsymbol{A}$ & $\boldsymbol{B}$ & $\boldsymbol{C}$ & $\boldsymbol{R}^{\mathbf{2}}$ \\
\hline $\mathbf{0 . 2}$ & 0.236 & -0.819 & 1.255 & 0.999 \\
\hline $\mathbf{0 . 5}$ & 0.595 & -1.534 & 1.626 & 0.999 \\
\hline $\mathbf{0 . 8}$ & 0.923 & -2.150 & 1.928 & 0.997 \\
\hline
\end{tabular}




\section{Figures}

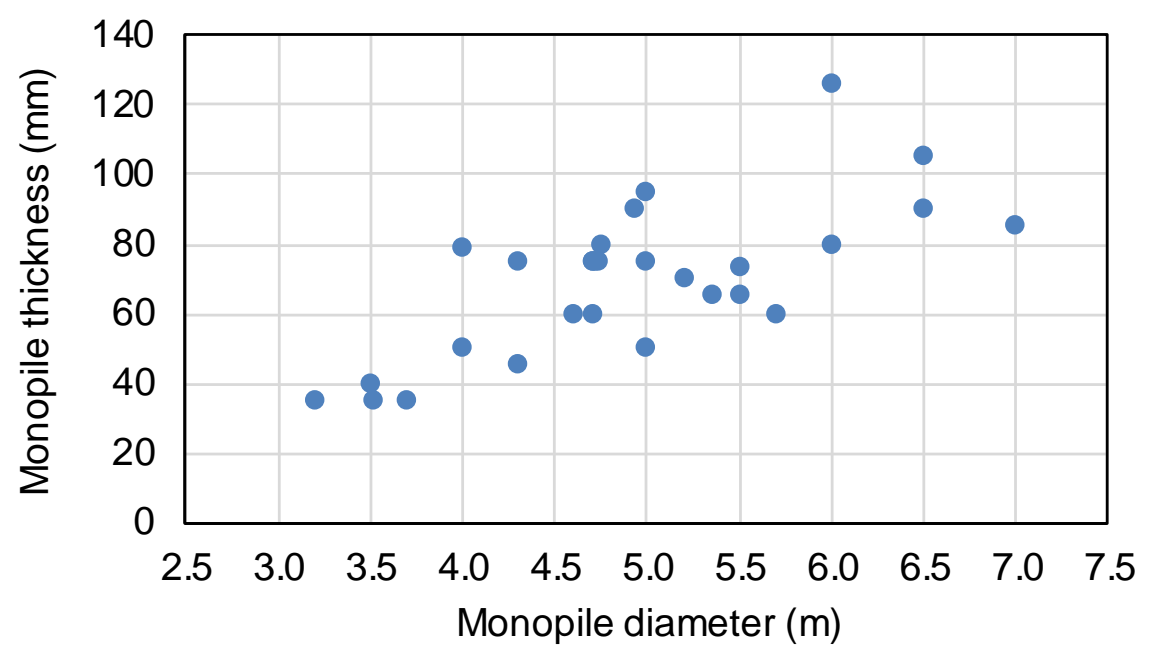

Figure 1: The thickness and diameter variation in some of the existing offshore wind turbine monopiles

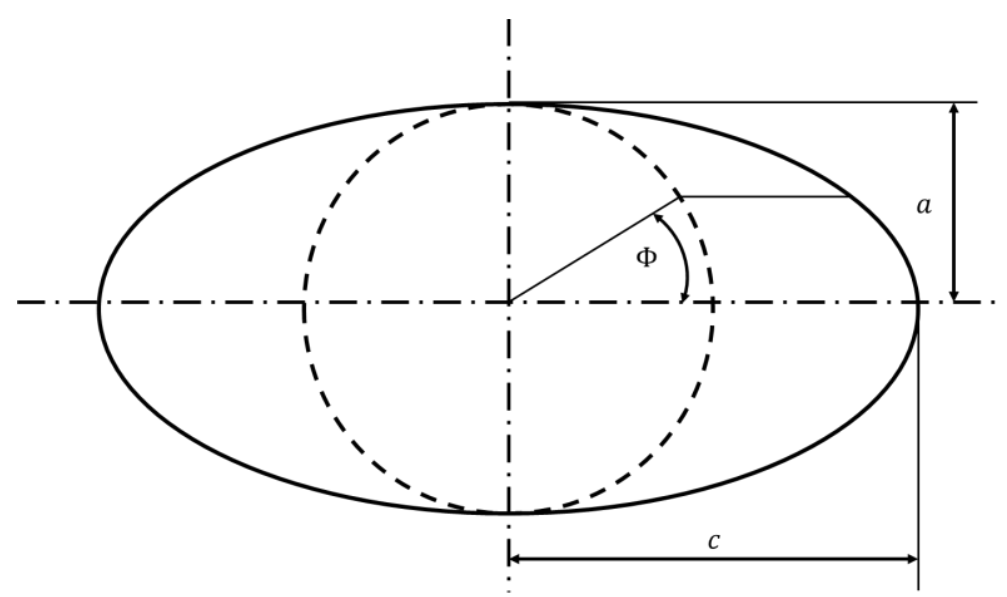

Figure 2: Crack configuration for Irwin's stress intensity factor equation for an elliptical crack in an infinite body [9] 

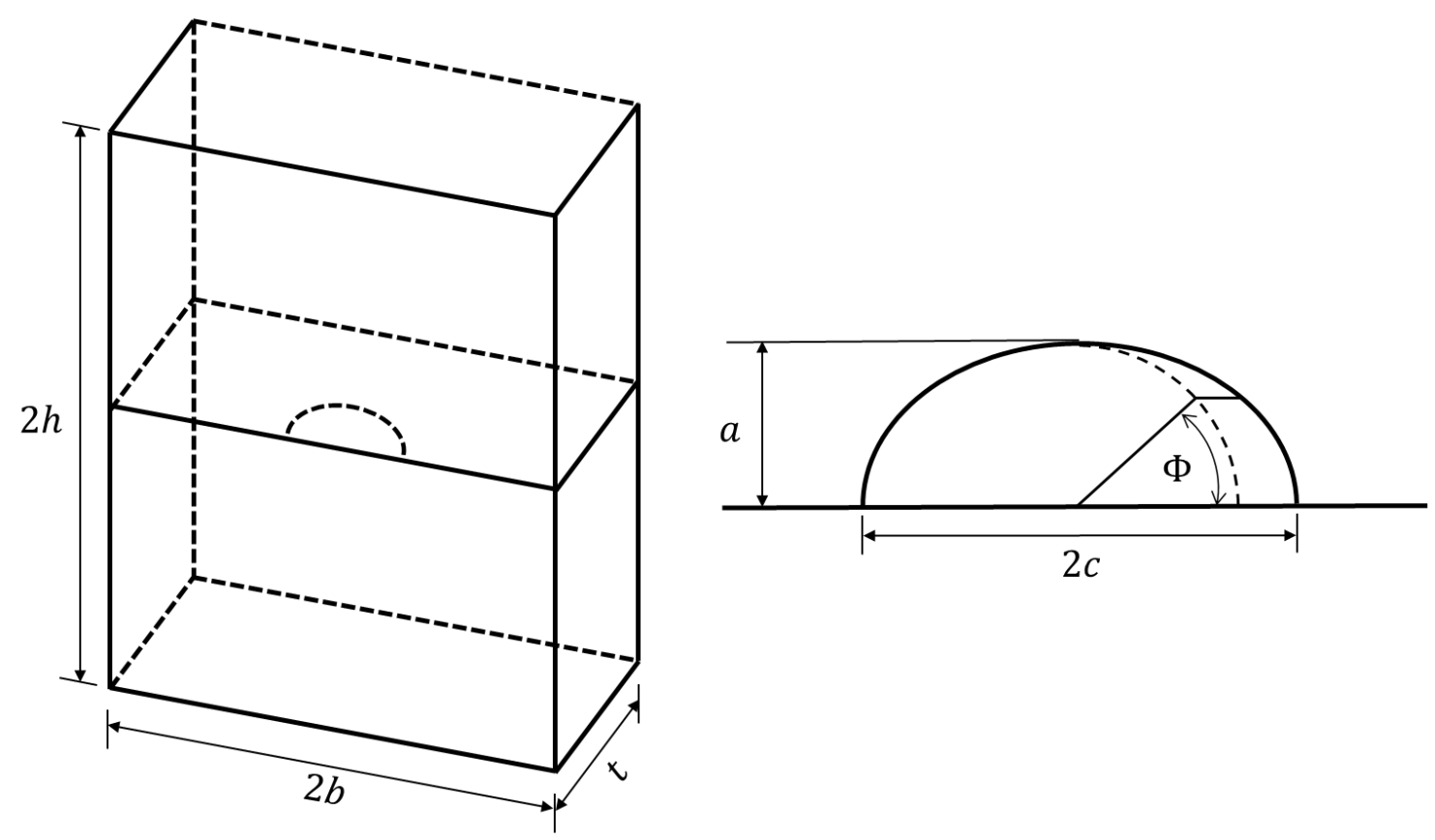

Figure 3: Geometry of the semi-elliptical surface crack in a finite plate under tension in N\&R stress intensity factor solutions [22]

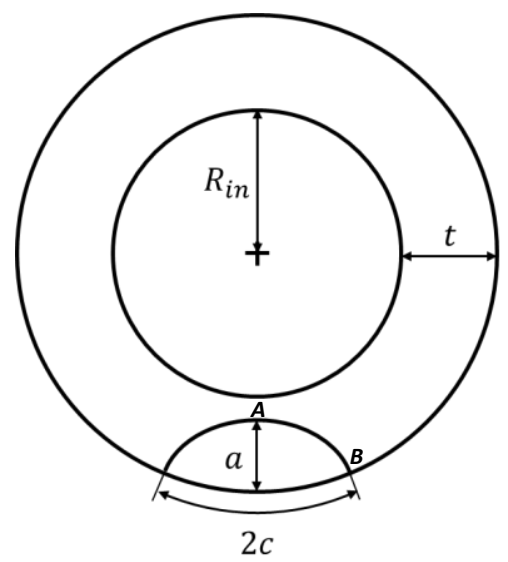

Figure 4: Pipe geometry considered for circumferential semi-elliptical surface crack stress intensity factor solutions proposed by $N \& R$ [21] 


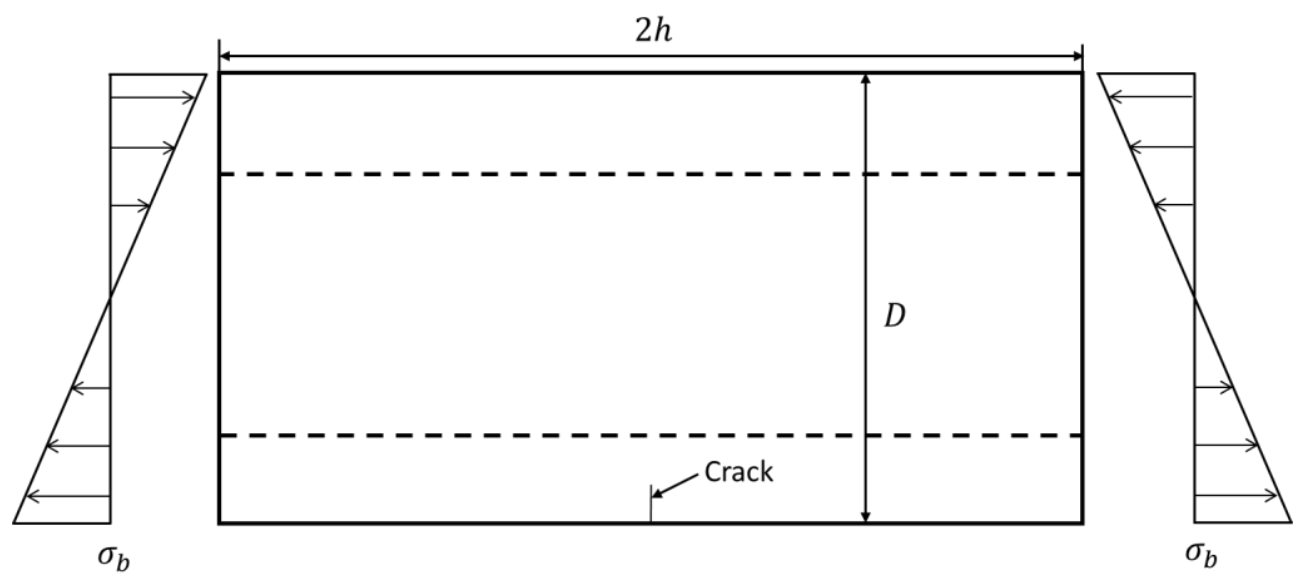

Figure 5: Geometry and loading conditions in N\&R stress intensity factor solutions for circumferential semi-elliptical surface cracks [21]

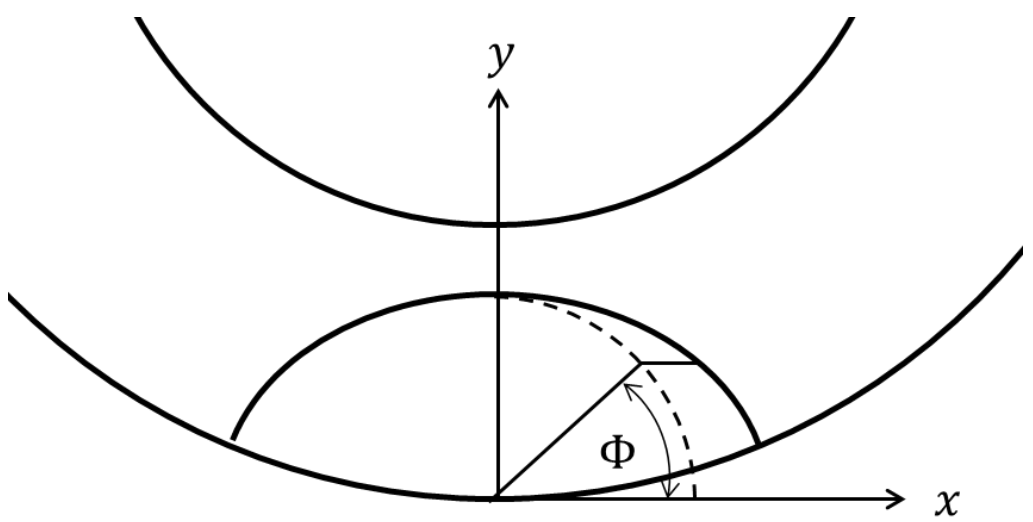

Figure 6: Coordinate system used by N\&R for circumferential semi-elliptical surface crack stress intensity factor solutions [21]

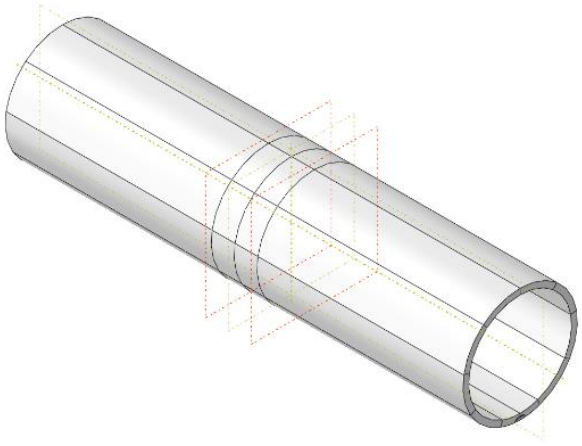

(a)

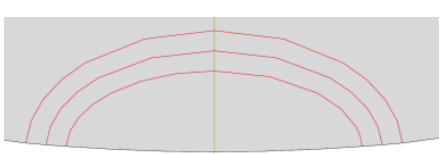

(b)

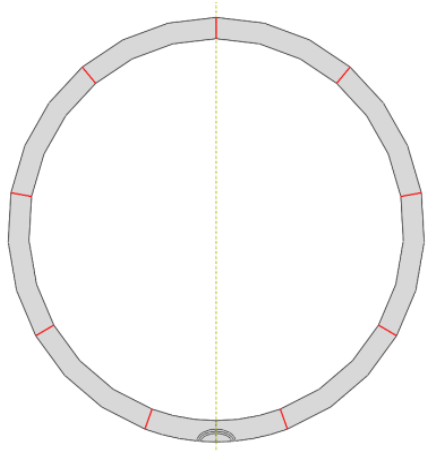

(c)

Figure 7: Partitioning strategy for finite element simulations on monopile geometry 


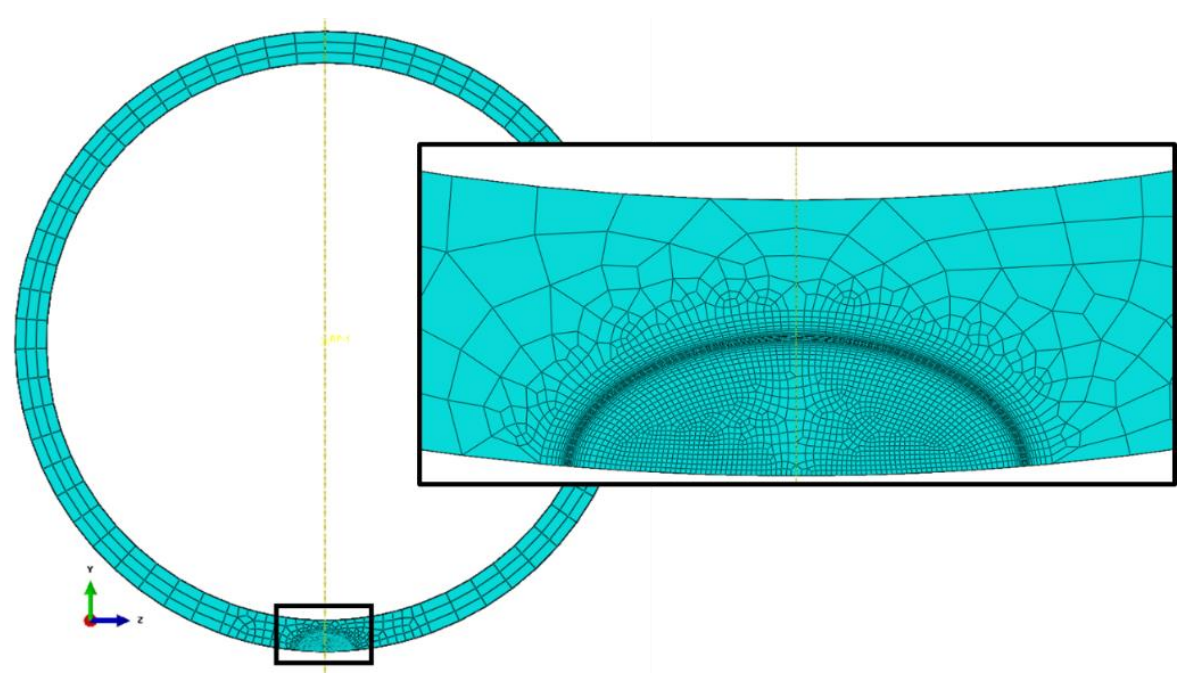

Figure 8: Mesh structure for finite element analysis (top view)

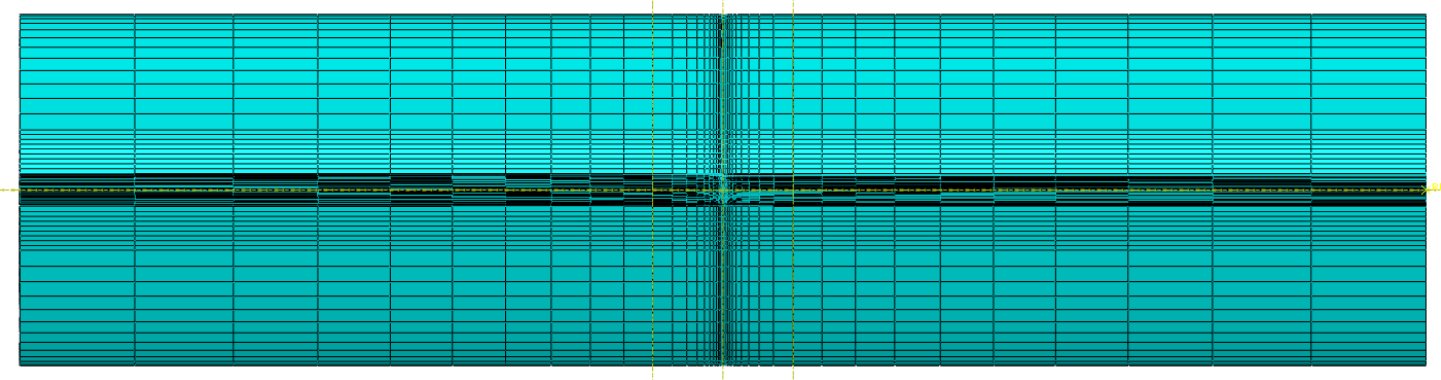

Figure 9: Mesh structure for finite element analysis (side view)

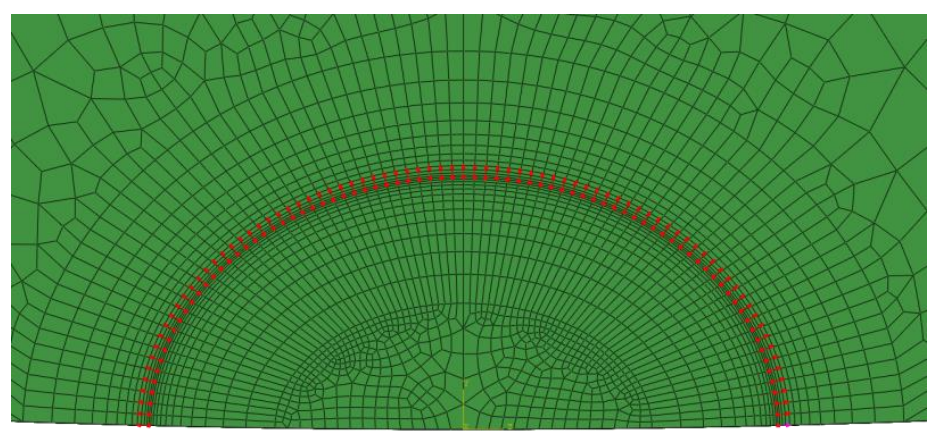

Figure 10: q-vector distribution at the crack front 


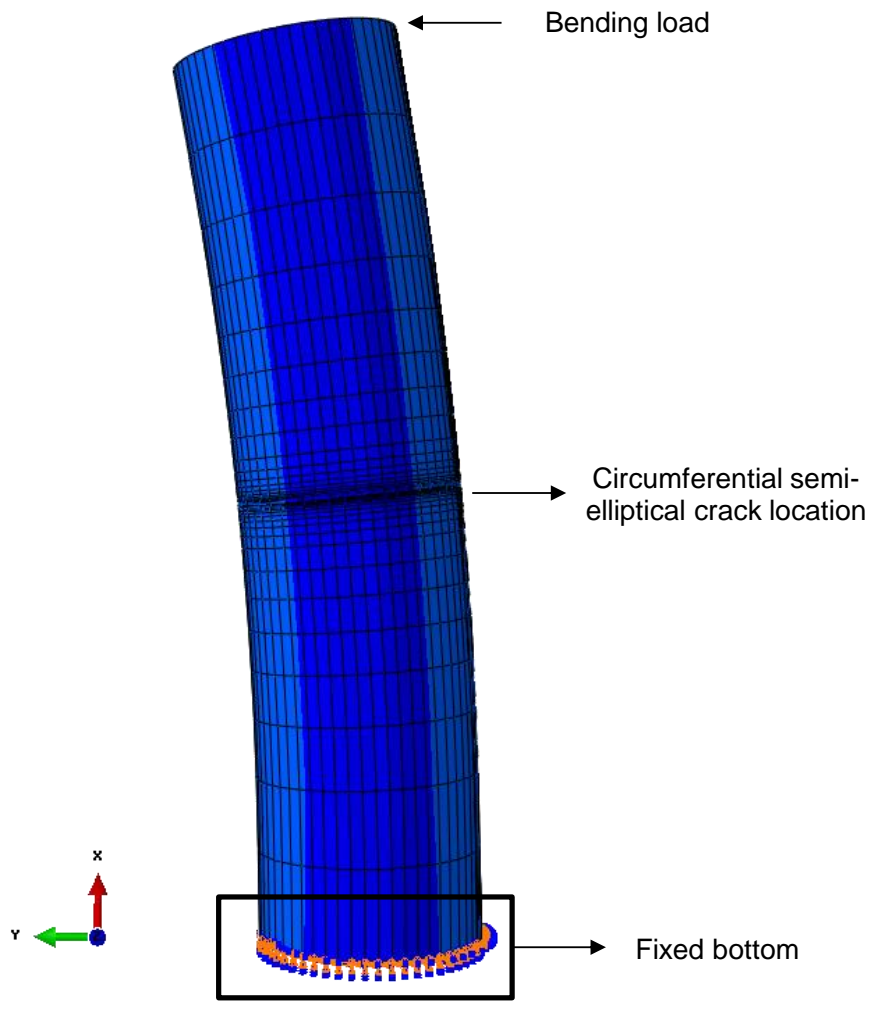

Figure 11: Boundary conditions applied on the monopile geometry

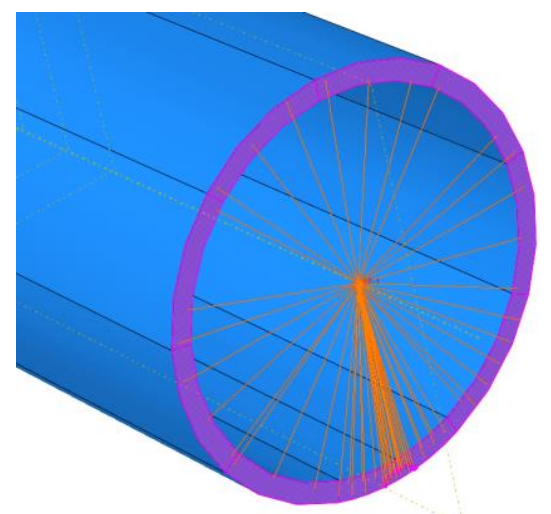

Figure 12: Coupling interaction used to apply the bending moment at one end of the monopile 


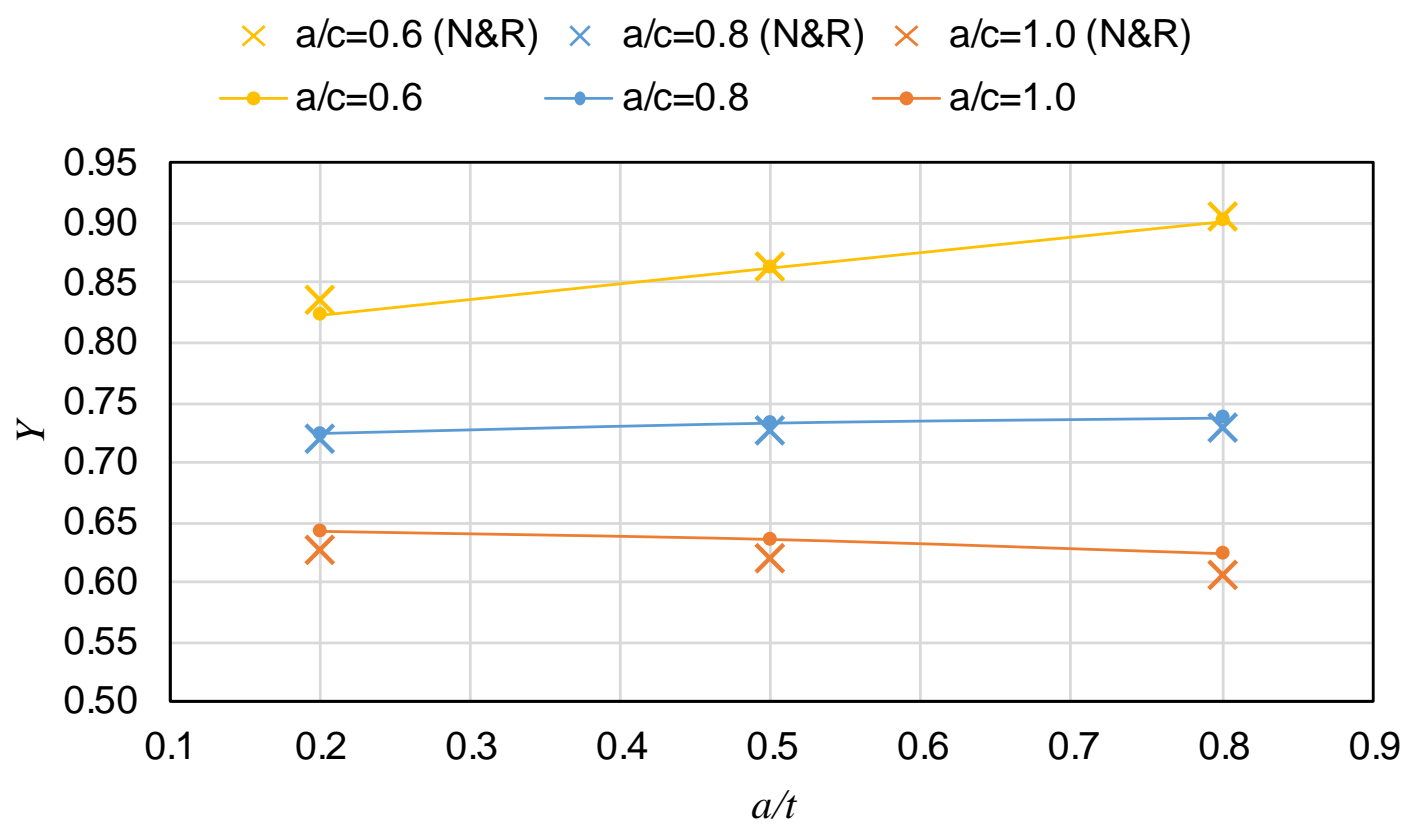

Figure 13: Comparison of $N \& R$ [21] and new shape function values for $R_{\text {out }} / t=5$ at the deepest point

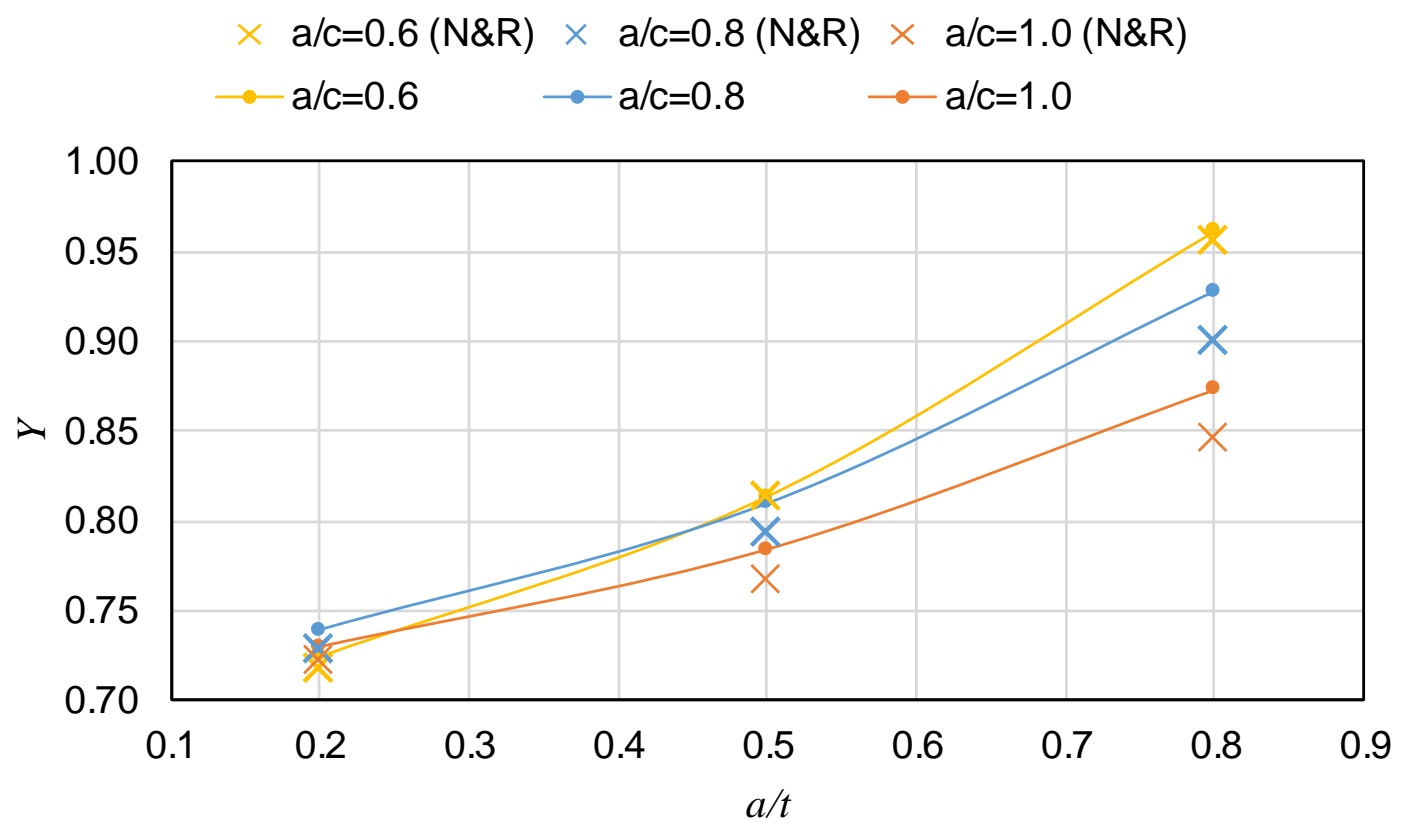

Figure 14: Comparison of $N \& R$ [21] and new shape function values for $R_{\text {out }} / t=5$ at the free surface point 


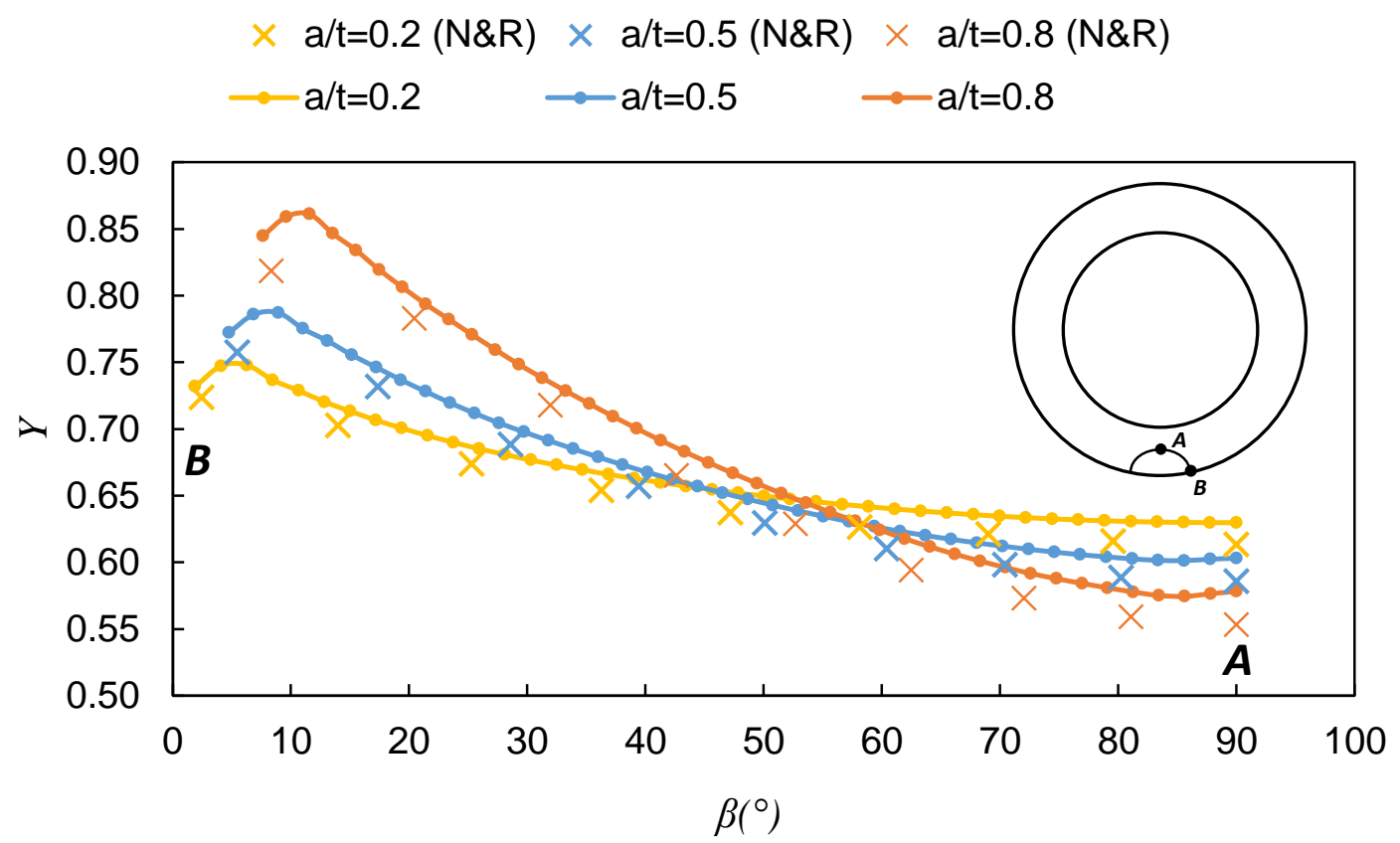

Figure 15: Variation of shape function solution along the crack front for $R_{\text {out }} / t=3$, $a / c=1.0$

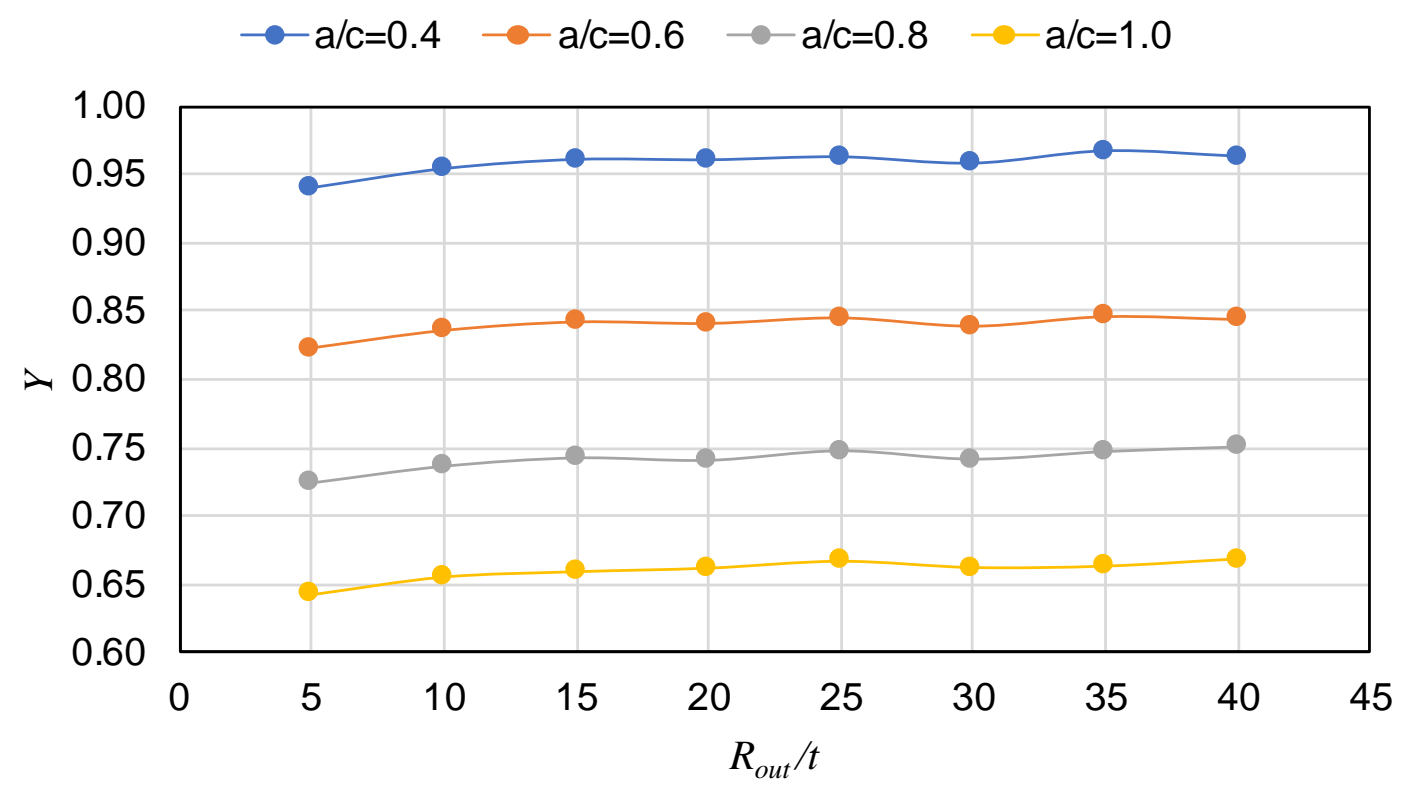

Figure 16: Shape function variation against $R_{\text {out }} / t$ ratio for different $a / c$ value and fixed $a / t$ of 0.2 


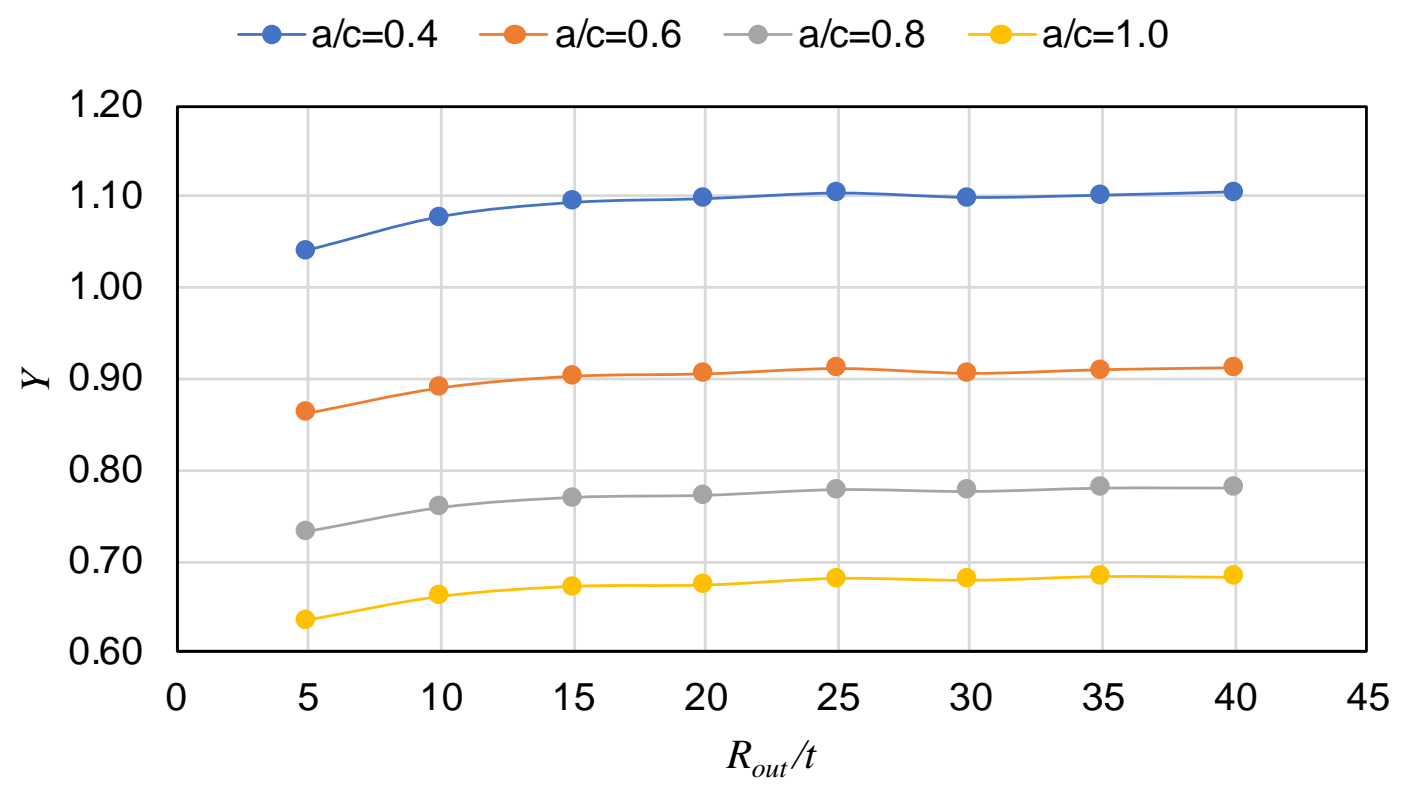

Figure 17: Shape function variation against $R_{\text {out }} / t$ ratio for different $a / c$ values and fixed $a / t$ of 0.5

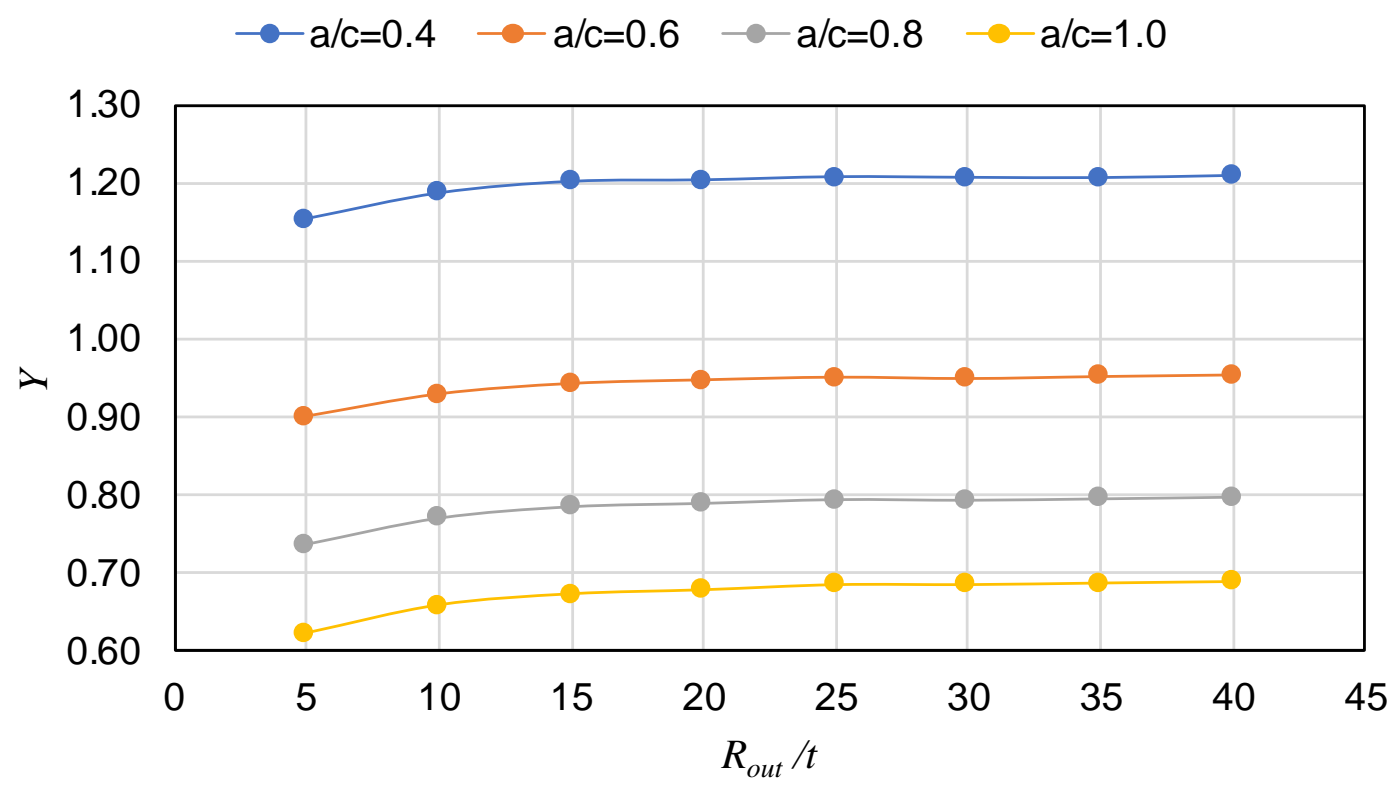

Figure 18: Shape function variation against $R_{\text {out }} / t$ ratio for different $a / c$ values and fixed $a / t$ of 0.8 


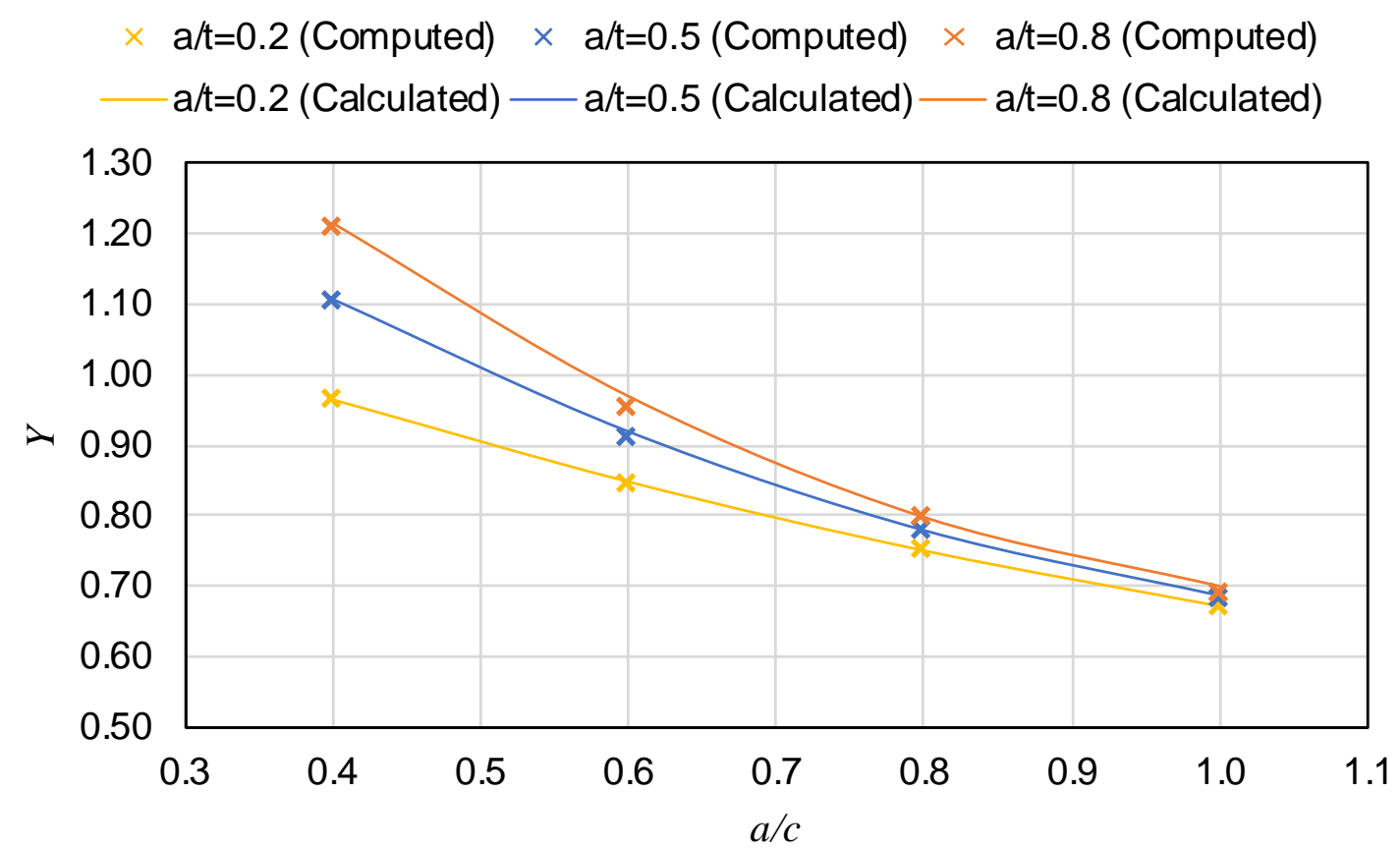

Figure 19: Dependency of new shape function solutions on $a / c$ and $a / t$ ratios (computed FE values are for $R_{\text {out }} / t=40$ and the calculated trends are obtained from Equation (20) which is valid for $R_{\text {out }} / t \geq 20$ )

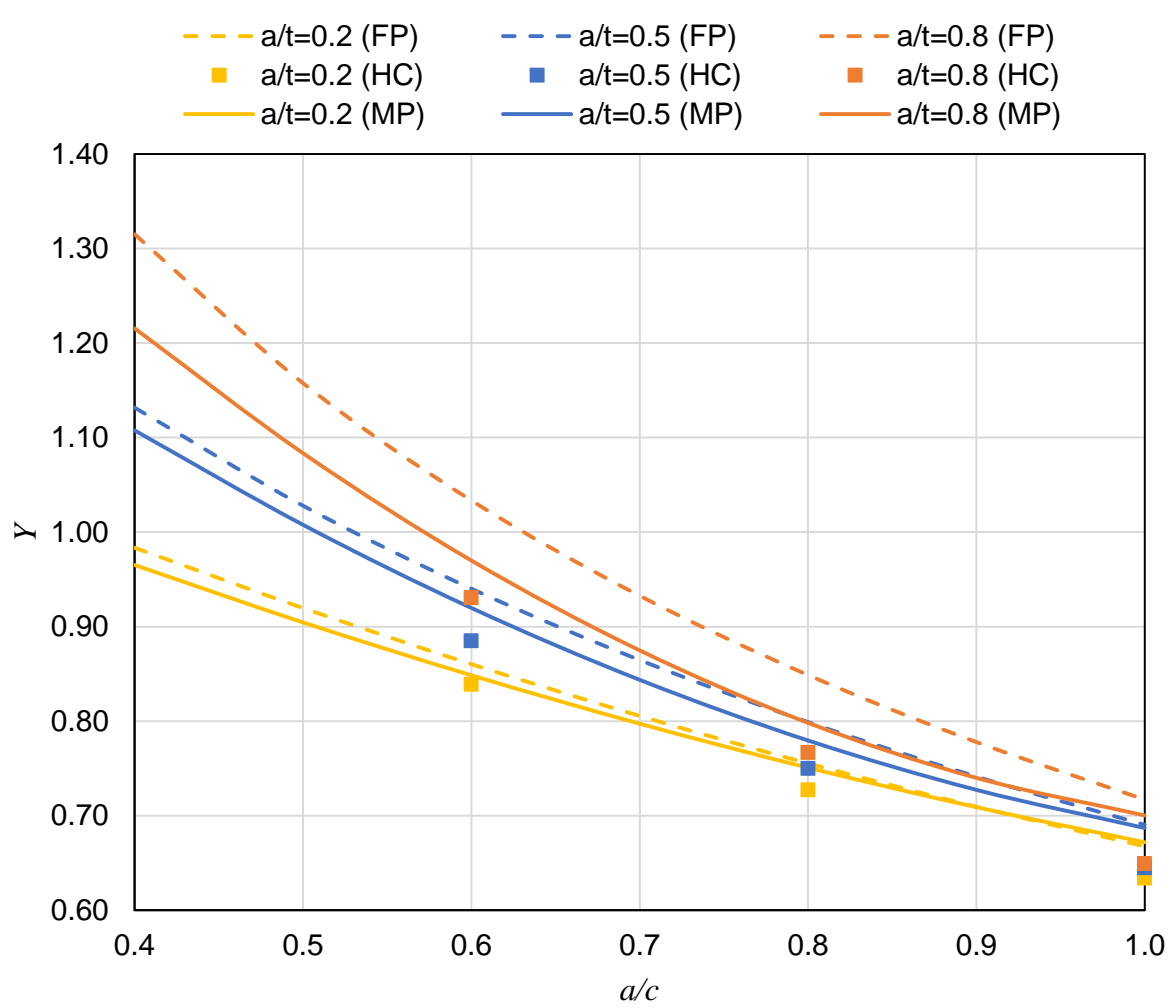

Figure 20: Comparison of the shape function values obtained from $N \& R$ solutions for the finite plate (FP), N\&R solution for hollow cylinder $(\mathrm{HC})$ with $R_{\text {ouf }} / t=11$ and the developed empirical equation (Equation (20)) for monopile (MP) 


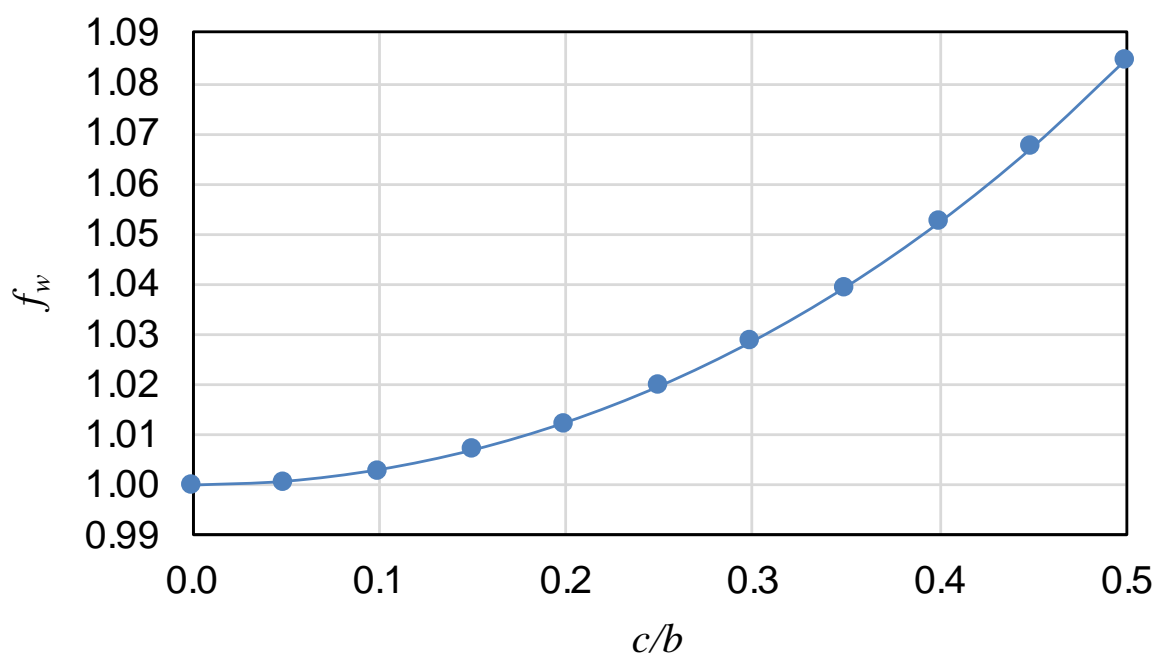

Figure 21: Variation of the width correction factor $f_{w}$ in $\mathrm{N} \& \mathrm{R}$ [22] solution against $c / b$ ratio

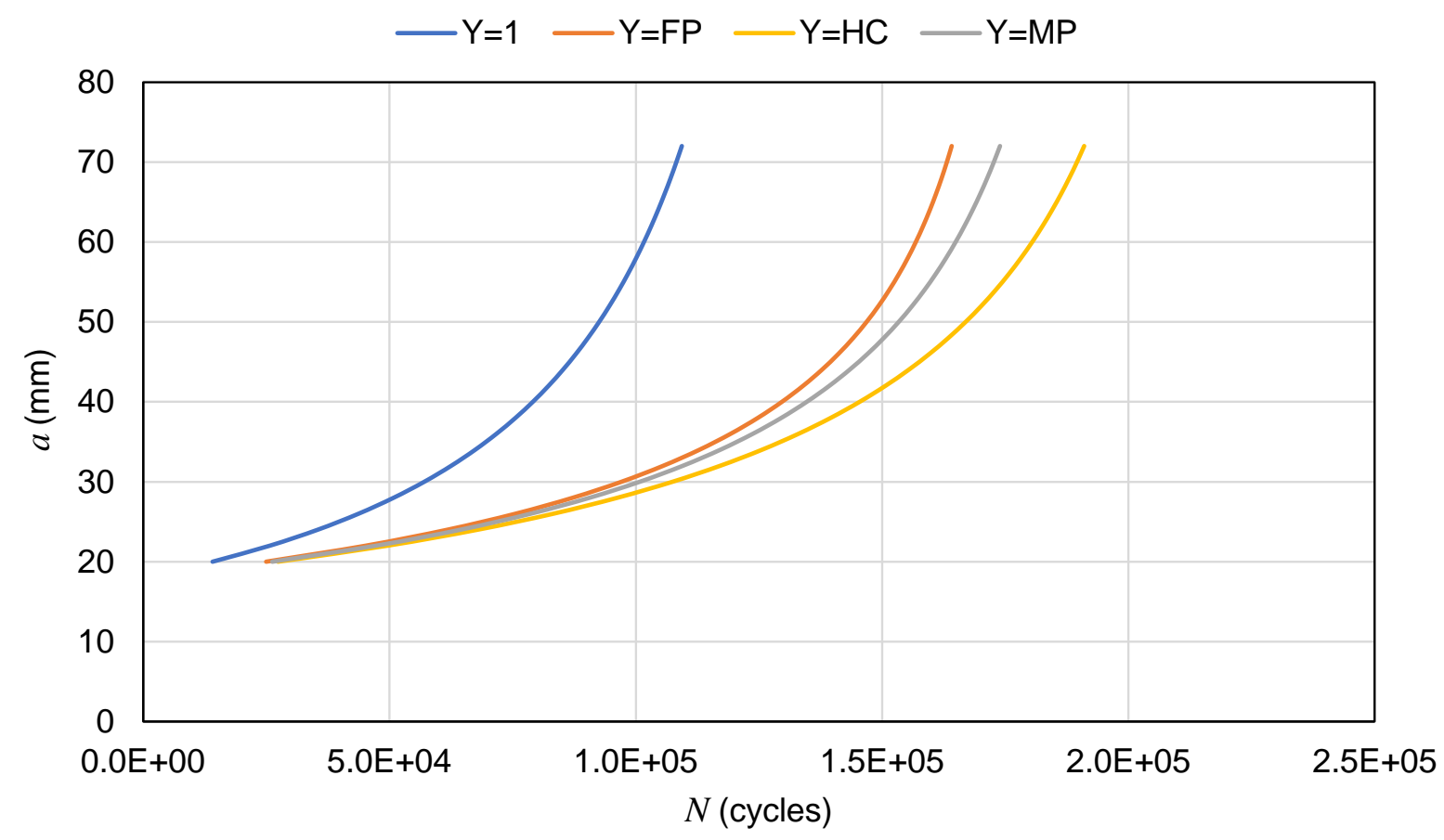

Figure 22: Crack growth estimation for base metal in seawater using different shape function solutions 


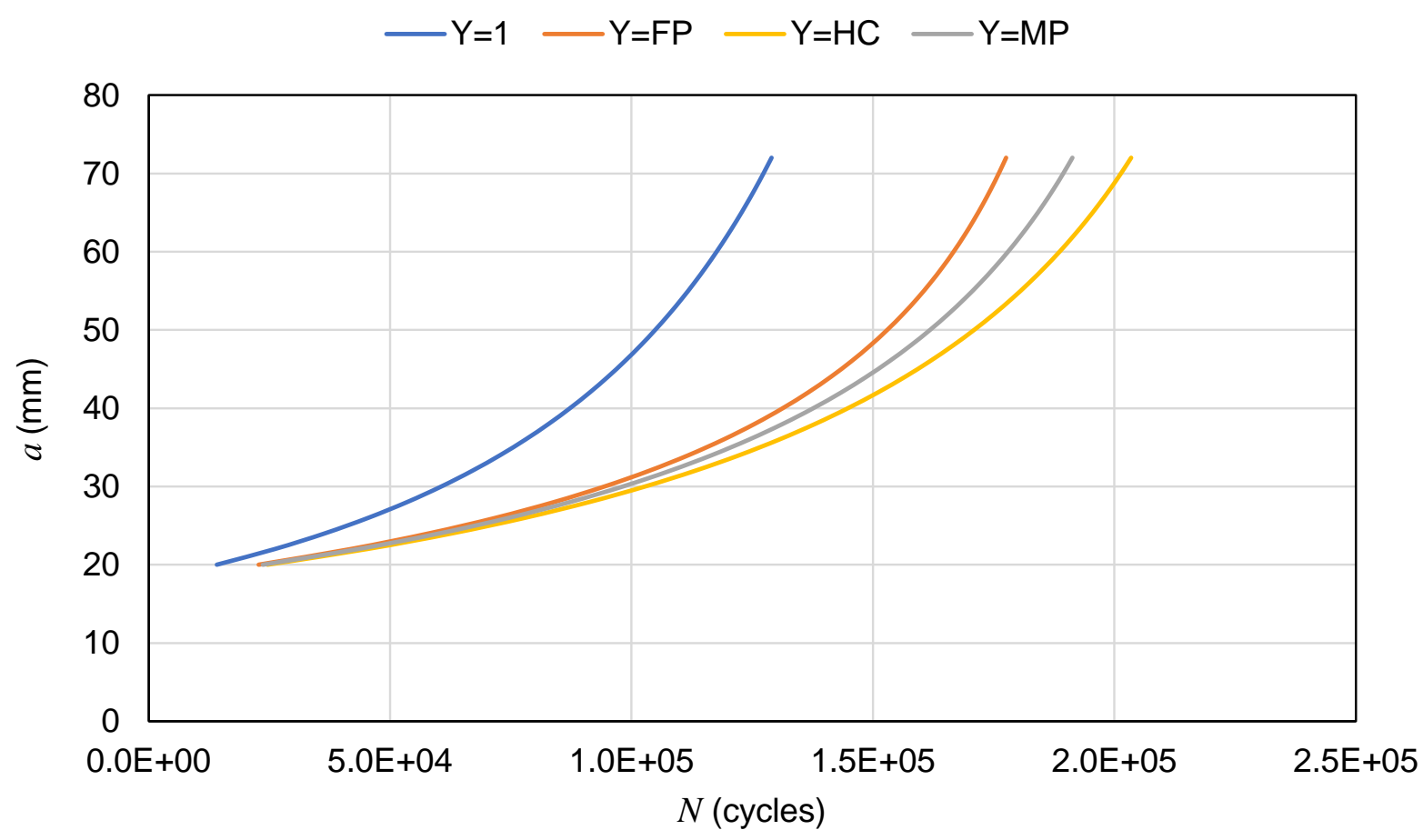

Figure 23: Crack growth estimation for the HAZ material in seawater using different shape function definitions 